\title{
Separation of Monochlorotoluene Isomers by Nonporous Adaptive Crystals of Perethylated Pillar[5]arene and Pillar[6]arene
}

\author{
Mengbin Wang, Jiong Zhou, Errui Li, Yujuan Zhou, Qing Li and Feihe Huang*
}

State Key Laboratory of Chemical Engineering, Center for Chemistry of High-Performance \& Novel Materials, Department of Chemistry, Zhejiang University, Hangzhou 310027, P. R. China; Fax and Tel: +86-571-8795-3189;

Email:fhuang@zju.edu.cn.

\section{Supporting Information (37 pages)}

$\begin{array}{ll}\text { 1. Materials } & \text { S2 }\end{array}$

2. Methods S2

3. Crystallography Data $\quad$ S4

4. Characterization of Activated EtP5 Crystals (EtP5 $\alpha)$ and EtP6 Crystals $\begin{array}{ll}\text { (EtP6 } \beta) & \text { S6 }\end{array}$

5. Single-Component Monochlorotoluene Isomer Absorption Experiments S9

6. Noncovalent Interactions Analysis in Single Crystal Structures $\quad$ S14

7. Uptake Study of p-Chlorotoluene in EtP5 $\alpha$ and EtP6 $\beta$ upon Absorption of p-Chlorotoluene/o-Chlorotoluene Mixtures with Various p-Chlorotoluene $\quad \mathrm{S} 18$ Fractions

8. Differential Scanning Calorimetric Study of p-Chlorotoluene-Loaded EtP5 $\alpha$ and EtP6 $\beta$

9. Separation of p-Chlorotoluene from Monochlorotulene Isomer Mixtures by EtP5 $\alpha$ and EtP6 $\beta$

10. Recyclability of EtP5 $\alpha$ and EtP6 $\beta \quad$ S32

11. ${ }^{1}$ H NMR spectra for Host-Guest Interactions Study in Solution $\quad$ S35

$\begin{array}{ll}\text { References } & \text { S37 }\end{array}$ 


\section{Materials}

p-Diethoxybenzene (99\%) was purchased and used as received. All other chemicals including $p$-chlorotoluene (PCT, $\geq 99 \%$ ), $o$-chlorotoluene (OCT, $\geq 99 \%$ ), and $m$-chlorotoluene (MCT, $\geq 99 \%$ ) were purchased and used as received. Both EtP5 and EtP6 were synthesized as described previously. ${ }^{\mathrm{S} 1}$ Activated crystalline EtP5 and EtP6 were referred to as EtP5 $\alpha$ and EtP6 $\beta$, respectively. Both EtP5 $\alpha$ and EtP6 $\beta$ were prepared according to reported procedures. ${ }^{\mathrm{S} 2}$

\section{Methods}

\subsection{Vapor Sorption Measurement}

PCT and OCT isomer sorption isotherms were measured via a Micromeritic 3Flex instrument. Samples were degassed under dynamic vacuum for 12 hours at $80{ }^{\circ} \mathrm{C}$ prior to each measurement. The isotherms were collected at $25{ }^{\circ} \mathrm{C}$ by monitoring the volume changes. The saturated vapor pressures of both PCT and OCT were calculated by the following equation:

$$
\log P_{\mathrm{i}}^{\mathrm{s}}(\mathrm{kPa})=A-(B /(T+C))
$$

where $P_{\mathrm{i}}^{\mathrm{s}}$ is the saturated vapor pressure of pure PCT or OCT, $T$ is Kelvin temperature, $A, B$ and $C$ are Antoine constants as reported. ${ }^{\mathrm{S} 3}$

\subsection{Powder X-Ray Diffraction}

Powder X-ray diffraction (PXRD) data were collected on a PANalytical X'Pert PRO X-ray diffractometer operating at $40 \mathrm{kV} / 40 \mathrm{~mA}$ using the $\mathrm{Cu} \mathrm{K} \mathrm{K}_{\alpha 1}(\lambda=1.540598 \AA)$ and $\mathrm{K}_{\alpha 2}(\lambda=1.544426 \AA)$.

\subsection{Thermogravimetric Analysis}

Thermogravimetric analysis (TGA) was carried out using a Q5000IR analyzer (TA Instruments) with an automated vertical overhead thermobalance. The samples were heated at $10{ }^{\circ} \mathrm{C} / \mathrm{min}$ using $\mathrm{N}_{2}$ as the protective gas.

\subsection{Differential Scanning Calorimetric study}

Differential Scanning Calorimetric study (DSC) was carried out using a DSC Q100 analyzer (TA Instruments). The samples were heated at $10{ }^{\circ} \mathrm{C} / \mathrm{min}$ using $\mathrm{N}_{2}$ as the protective gas.

\subsection{Single Crystal Growth}

Single crystals of PCT-loaded EtP5 or EtP6 were grown by cooling-induced crystallization: 5 mg of 
dry EtP5 or EtP6 powder were put in a small vial where $0.5 \mathrm{~mL}$ of PCT was added and the vial was heated until all the powder was dissolved. The resultant transparent solution was allowed to cool down to give nice colorless crystals. Single crystals of OCT-loaded EtP6 were grown by volatilization: $5 \mathrm{mg}$ of dry EtP6 powder were put in a small vial where $0.5 \mathrm{~mL}$ of OCT was added and the vial was heated until all the powder was dissolved. The colorless crystals were got by volatilization for a few days.

\subsection{Single Crystal X-ray Diffraction}

Single crystal X-ray diffraction data for PCT-loaded EtP5, PCT-loaded EtP6 and OCT-loaded EtP6 were collected on a Bruker D8 VENTURE CMOS X-ray diffractometer with a graphite monochromated Mo Ka radiation $(\lambda=0.71073 \AA)$.

\subsection{Solution ${ }^{1}$ H NMR Spectroscopy}

${ }^{1} \mathrm{H}$ NMR spectra were recorded with a Bruker Avance DMX 400 spectrometer.

\subsection{Gas Chromatography}

Head Space Gas Chromatography (HS-GC) Analysis: HS-GC measurements were carried out using an Agilent 7890B instrument configured with an FID detector and a DB-624 column $(30 \mathrm{~m} \times 0.53 \mathrm{~mm} \times$ $3.0 \mu \mathrm{m})$. Samples were analyzed using headspace injections and were performed by incubating the sample at $100{ }^{\circ} \mathrm{C}$ for $10 \mathrm{~min}$ followed by sampling $1 \mathrm{~mL}$ of the headspace. The following GC method was used: the oven was programmed from $50{ }^{\circ} \mathrm{C}$, and ramped in $10{ }^{\circ} \mathrm{C} \mathrm{min}-1$ increments to $150{ }^{\circ} \mathrm{C}$ with 15 min hold; the total run time was $25 \mathrm{~min}$; the injection temperature was $250{ }^{\circ} \mathrm{C}$; the detector temperature was $280{ }^{\circ} \mathrm{C}$ with nitrogen, air, and make-up flow rates of 35,350 , and $35 \mathrm{~mL} \mathrm{~min}^{-1}$, respectively; helium (carrier gas) flow rate was $3.0 \mathrm{~mL} \mathrm{~min}^{-1}$. The samples were injected in the split mode $(30: 1)$. 


\section{Crystallography Data}

Table S1. Experimental single crystal X-ray data for PCT-loaded or OCT-loaded pillar[ $n] \operatorname{arene}$ structures.

\begin{tabular}{|c|c|c|}
\hline Formula & $(\mathbf{P C T})_{3} @(\text { EtP5 })_{2}$ & PCT@EtP6 \\
\hline Crystallization Solvent & $p$-chlorotoluene & $p$-chlorotoluene \\
\hline Wavelength $[\AA]$ & 0.71073 & 0.71073 \\
\hline Collection Temperature (K) & $273(2)$ & $296(2) \mathrm{K}$ \\
\hline Formula & $\mathrm{C}_{131} \mathrm{H}_{164} \mathrm{Cl}_{3} \mathrm{O}_{20}$ & $\mathrm{C}_{73} \mathrm{H}_{92} \mathrm{Cl} \mathrm{O}_{12}$ \\
\hline Formula Weight & 2164.97 & 1196.92 \\
\hline Crystal System & Monoclinic & Monoclinic \\
\hline Space Group & $\mathrm{P} 2(1) / \mathrm{n}$ & $\mathrm{P} 2(1) / \mathrm{n}$ \\
\hline$a[\AA]$ & $11.6711(4)$ & $a=11.607(3)$ \\
\hline$b[\AA]$ & $21.5510(6)$ & $12.917(3)$ \\
\hline$c[\AA]$ & $23.8501(8)$ & $22.363(5)$ \\
\hline$\alpha\left[^{\circ}\right]$ & 90 & 90 \\
\hline$\beta\left[^{0}\right]$ & $95.321(1)$ & $91.310(8)$ \\
\hline$\gamma\left[^{0}\right]$ & 90 & 90 \\
\hline$V\left[\AA^{3}\right]$ & $5973.0(3)$ & $3351.9(13)$ \\
\hline$Z$ & 2 & 2 \\
\hline$D_{\text {calcd }}\left[\mathrm{g} \mathrm{cm}^{-3}\right]$ & 1.204 & 1.186 \\
\hline Absorption coefficient $\left(\mathrm{mm}^{-1}\right)$ & 0.144 & 0.117 \\
\hline$F(000)$ & 2322.0 & 1286 \\
\hline Theta range $\left[{ }^{\circ}\right]$ & $2.96-25.00$ & $2.00-25.47$ \\
\hline Reflections collected / unique & $30634 / 10457[\mathrm{R}(\mathrm{int})=0.0462]$ & $20867 / 6147[\mathrm{R}(\mathrm{int})=0.0667]$ \\
\hline Data / restraints / parameters & $10457 / 0 / 706$ & 6147 / 0 / 394 \\
\hline Final $R$ indices $[I>2 \sigma(I)]$ & $R_{1}=0.0672, w R_{2}=0.1723$ & $R_{1}=0.0723, w R_{2}=0.1851$ \\
\hline$R$ indices (all data) & $R_{1}=0.0944, w R_{2}=0.1885$ & $R_{1}=0.1492, w R_{2}=0.2287$ \\
\hline Goodness-of-fit on $F^{2}$ & 1.075 & 1.017 \\
\hline $\begin{array}{l}\text { Largest difference peak and } \\
\qquad \text { hole }\left[\mathrm{e}^{\left.-\mathrm{A}^{-3}\right]}\right.\end{array}$ & 1.817 and -1.516 & 0.458 and -0.375 \\
\hline CCDC & 1921756 & 1921759 \\
\hline
\end{tabular}


Formula

Crystallization Solvent

Wavelength $[\AA]$

Collection Temperature (K)

Formula

Formula Weight

Crystal System

Space Group

$a[\AA]$

$b[\AA]$

$c[\AA]$

$\alpha\left[^{\circ}\right]$

$\beta\left[^{0}\right]$

$\gamma\left[{ }^{\circ}\right]$

$V\left[\AA^{3}\right]$

Z

$D_{\text {calcd }}\left[\mathrm{g} \mathrm{cm}^{-3}\right]$

Absorption coefficient $\left(\mathrm{mm}^{-1}\right)$

$F(000)$

Theta range $\left[{ }^{\circ}\right]$

Reflections collected / unique

Data / restraints / parameters

Final $R$ indices $[I>2 \sigma(I)]$

$R$ indices (all data)

Goodness-of-fit on $F^{2}$

Largest difference peak and

hole $\left[\mathrm{e} . \mathrm{A}^{-3}\right.$ ]
OCT@EtP6

$o$-chlorotoluene

0.71073

273

$\mathrm{C}_{73} \mathrm{H}_{91} \mathrm{Cl} \mathrm{O}_{12}$

1195.90

Monoclinic

$\mathrm{P} 2(1) / \mathrm{n}$

$11.2674(5)$

12.9976(5)

22.3812(11)

90

91.927(2)

90

$3275.9(3)$

2

1.212

0.120

1284

$2.971-26.425$

$35208 / 6680[\mathrm{R}(\mathrm{int})=0.0490]$

6680 / 64 / 419

$R_{1}=0.0622, w R_{2}=0.1624$

$R_{1}=0.0876, w R_{2}=0.1852$

1.049

0.796 and -0.632 

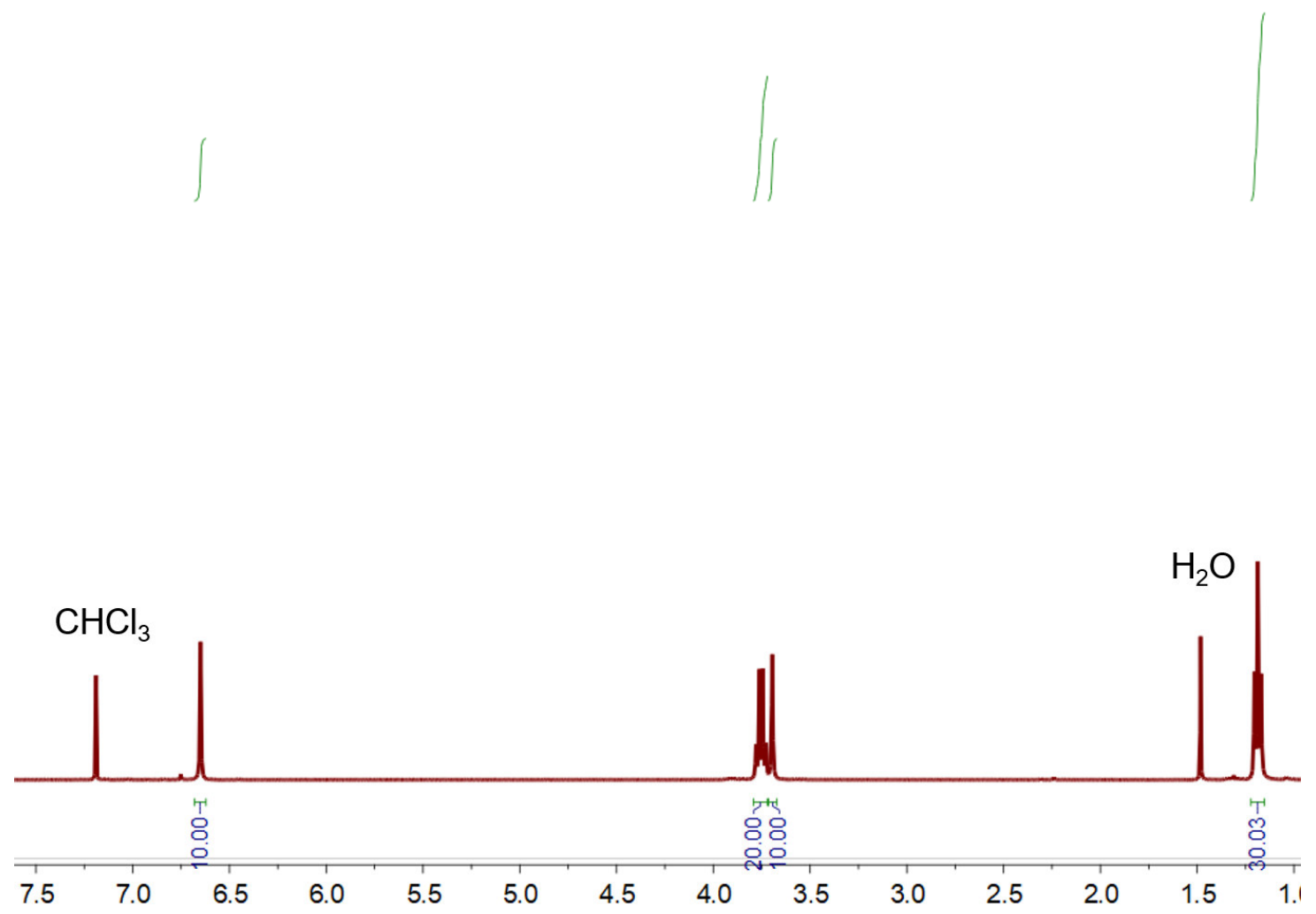

Figure S1. ${ }^{1} \mathrm{H}$ NMR spectrum (400 MHz, chloroform- $d$, $298 \mathrm{~K}$ ) of EtP5 $\alpha$.

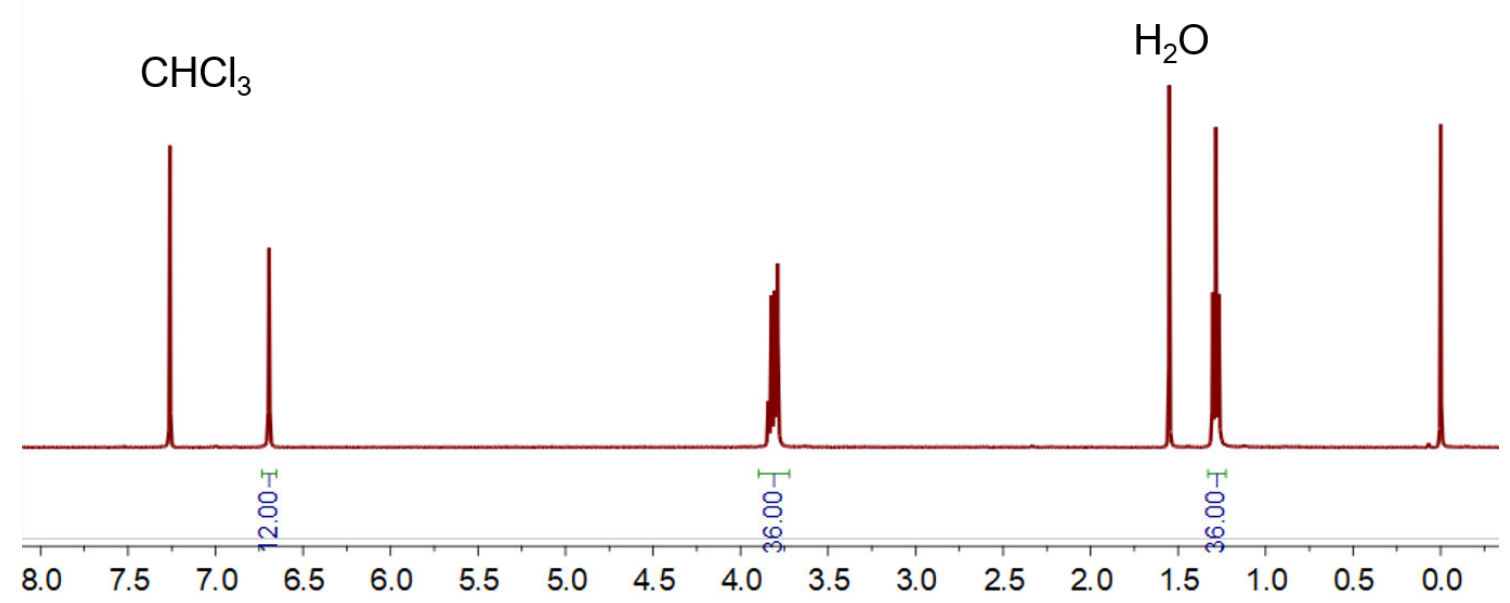

Figure S2. ${ }^{1} \mathrm{H}$ NMR spectrum (400 MHz, chloroform- $d$, $298 \mathrm{~K}$ ) of EtP6 $\beta$. 


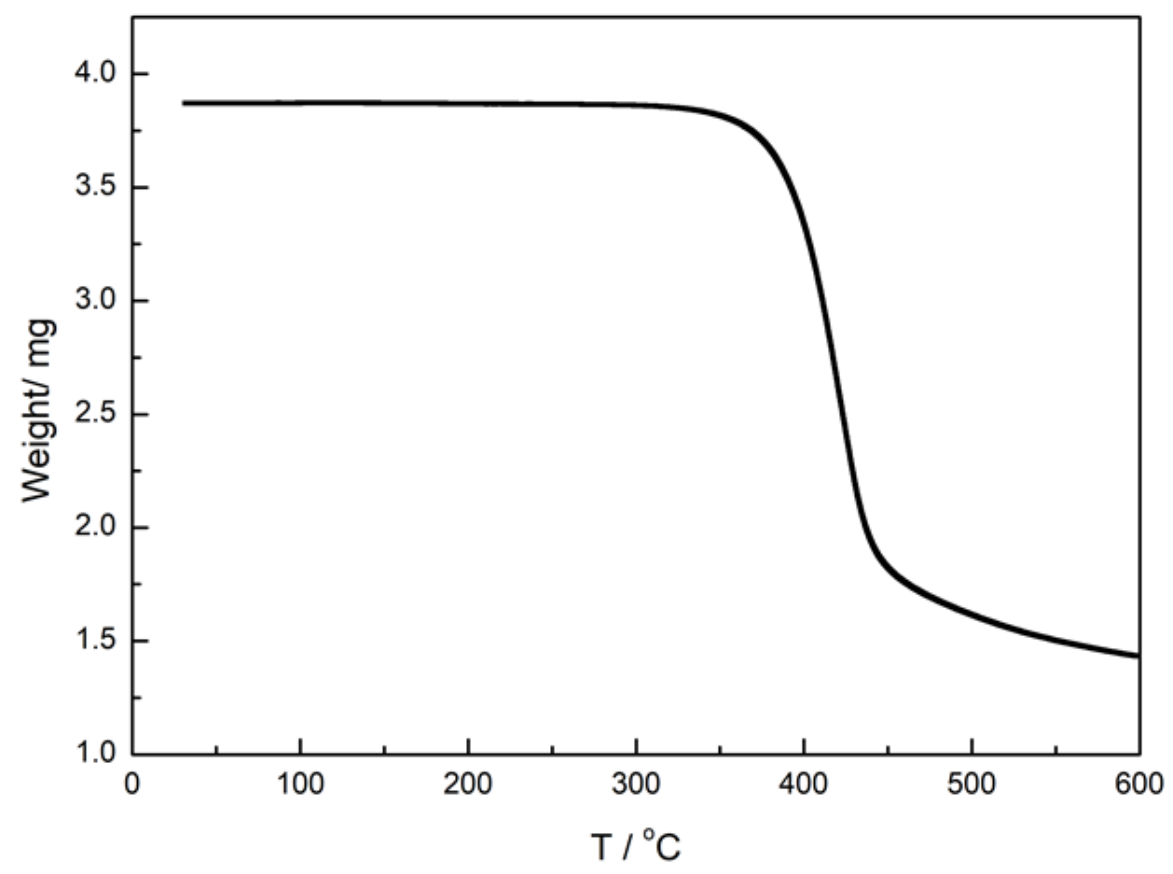

Figure S3. Thermogravimetric analysis of activated EtP5 $\alpha$.

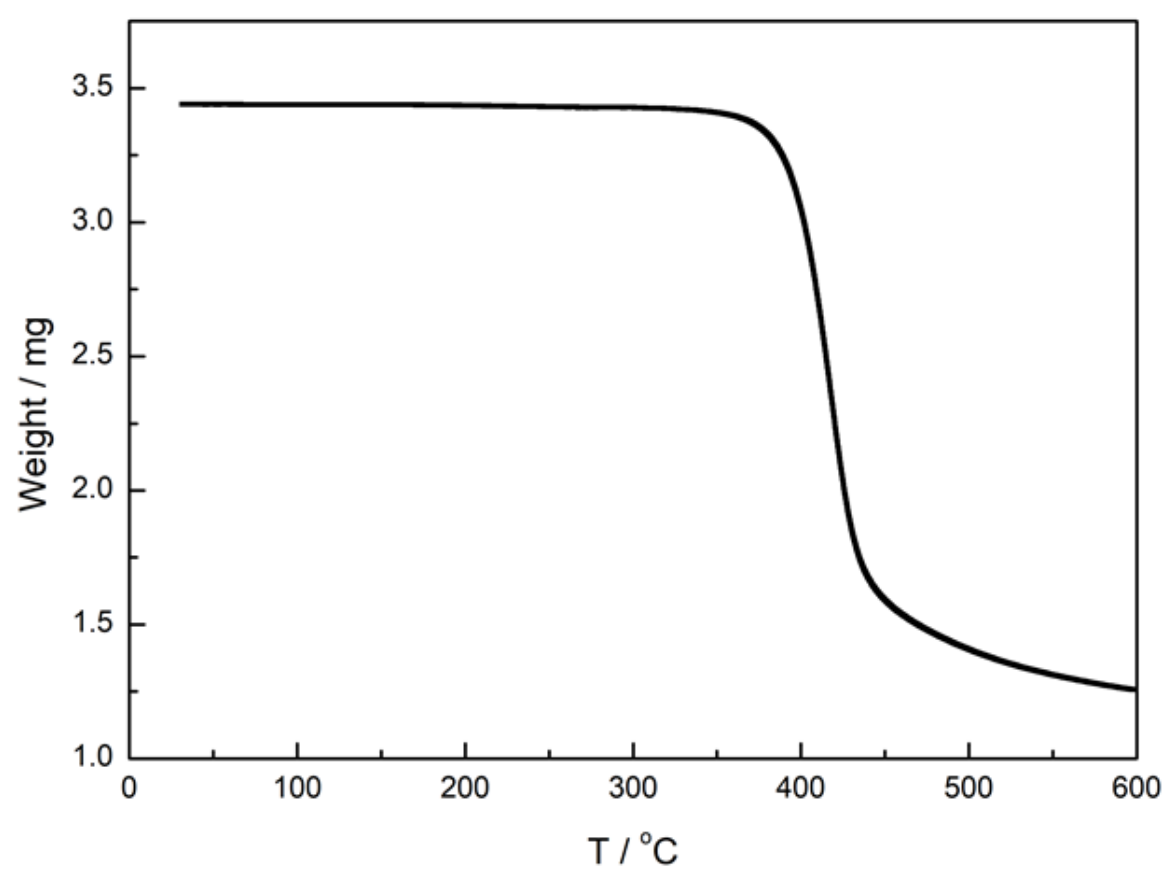

Figure S4. Thermogravimetric analysis of activated EtP6 $\beta$. 


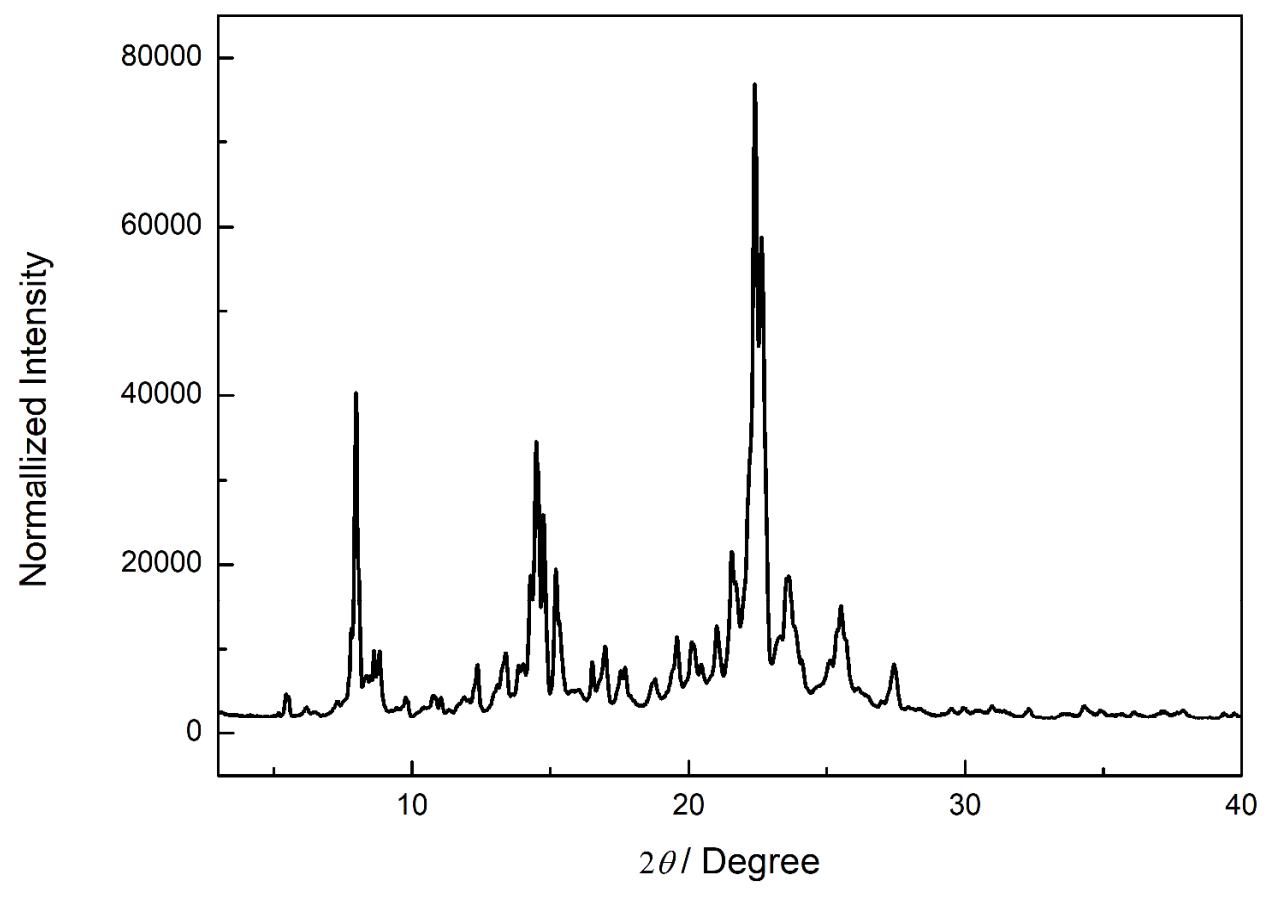

Figure S5. Powder X-ray diffraction pattern of EtP5 $\alpha$.

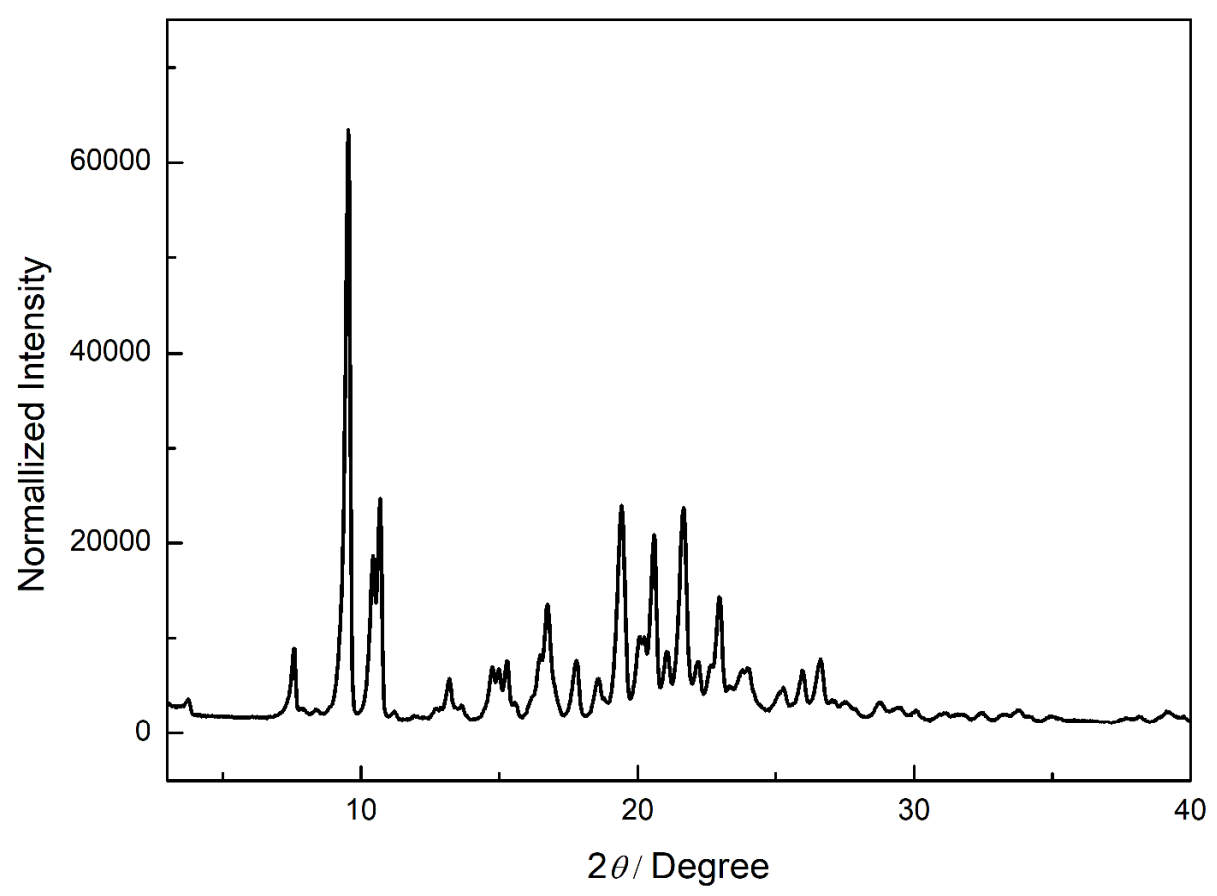

Figure S6. Powder X-ray diffraction pattern of EtP6 $\beta$. 


\section{Single-Component Monochlorotoluene Isomer Adsorption Experiments}

An open $5 \mathrm{~mL}$ vial containing $20 \mathrm{mg}$ of guest-free $\mathbf{E t P 5} \alpha$ or EtP6 $\beta$ adsorbent was placed in a sealed $20 \mathrm{~mL}$ vial containing $1 \mathrm{~mL}$ of PCT or OCT. The crystals after absorption were heated at $50{ }^{\circ} \mathrm{C}$ under vacuum for $30 \mathrm{~min}$ to remove the vapor molecules on the crystal surfaces. Time-dependent EtP5 $\alpha$ or EtP6 $\beta$ solid-vapor sorption plots were measured by completely dissolving the crystals and measuring the molar ratio of PCT or OCT to EtP6 or EtP5 by ${ }^{1} \mathrm{H}$ NMR every 4 hours. Thermogravimetric analysis experiments were performed using EtP5 $\alpha$ or EtP6 $\beta$ crystals after vapor sorption.

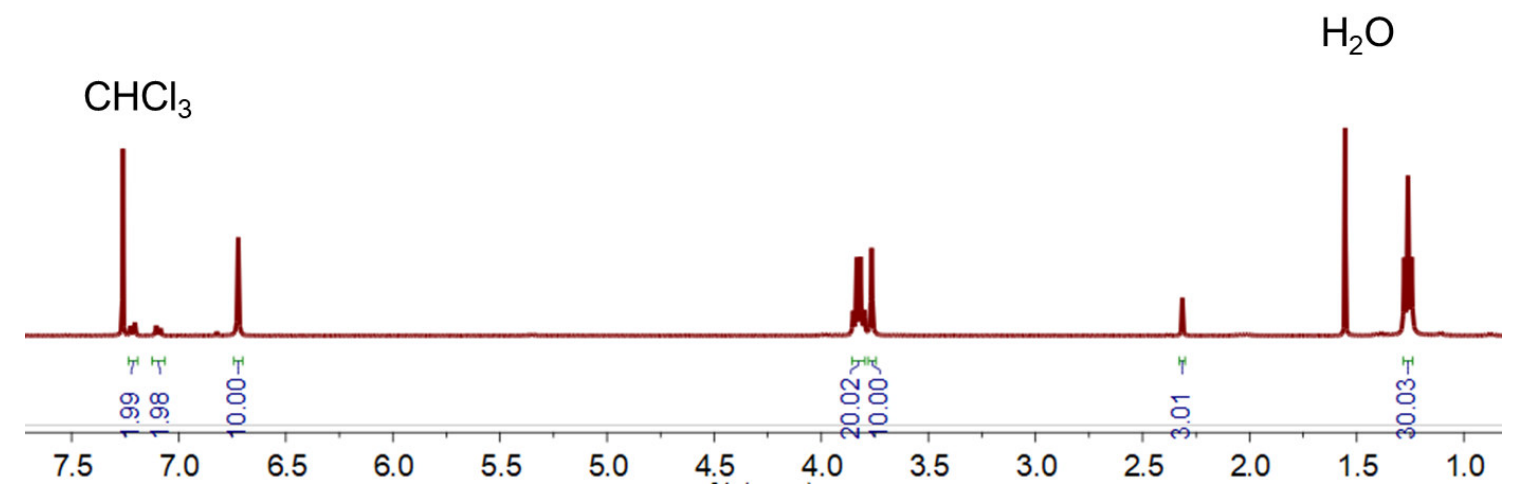

Figure S7. ${ }^{1} \mathrm{H}$ NMR spectrum (400 MHz, chloroform- $d, 298 \mathrm{~K}$ ) of EtP5 $\alpha$ after sorption of PCT vapor for $24 \mathrm{~h}$. 


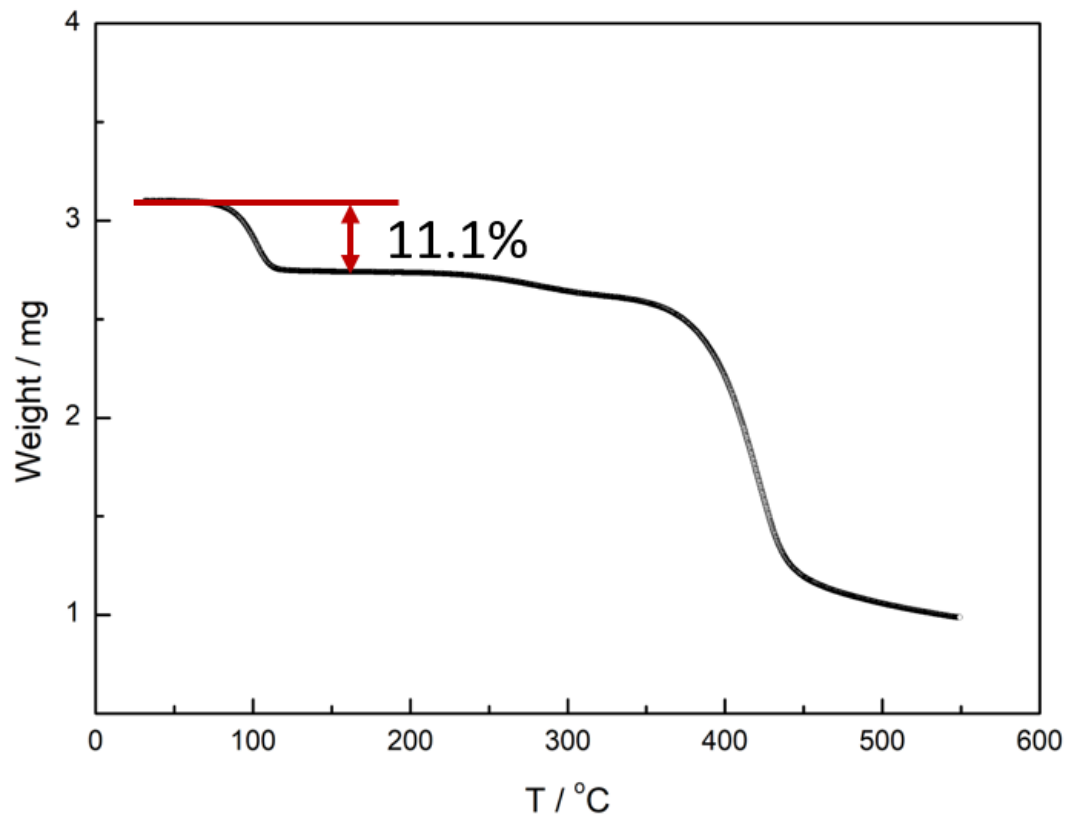

Figure S8. Thermogravimetric analysis of EtP5 $\alpha$ after absorption of PCT vapor for $24 \mathrm{~h}$. The weight loss below $150^{\circ} \mathrm{C}$ can be calculated as one PCT molecule per EtP5 molecule.
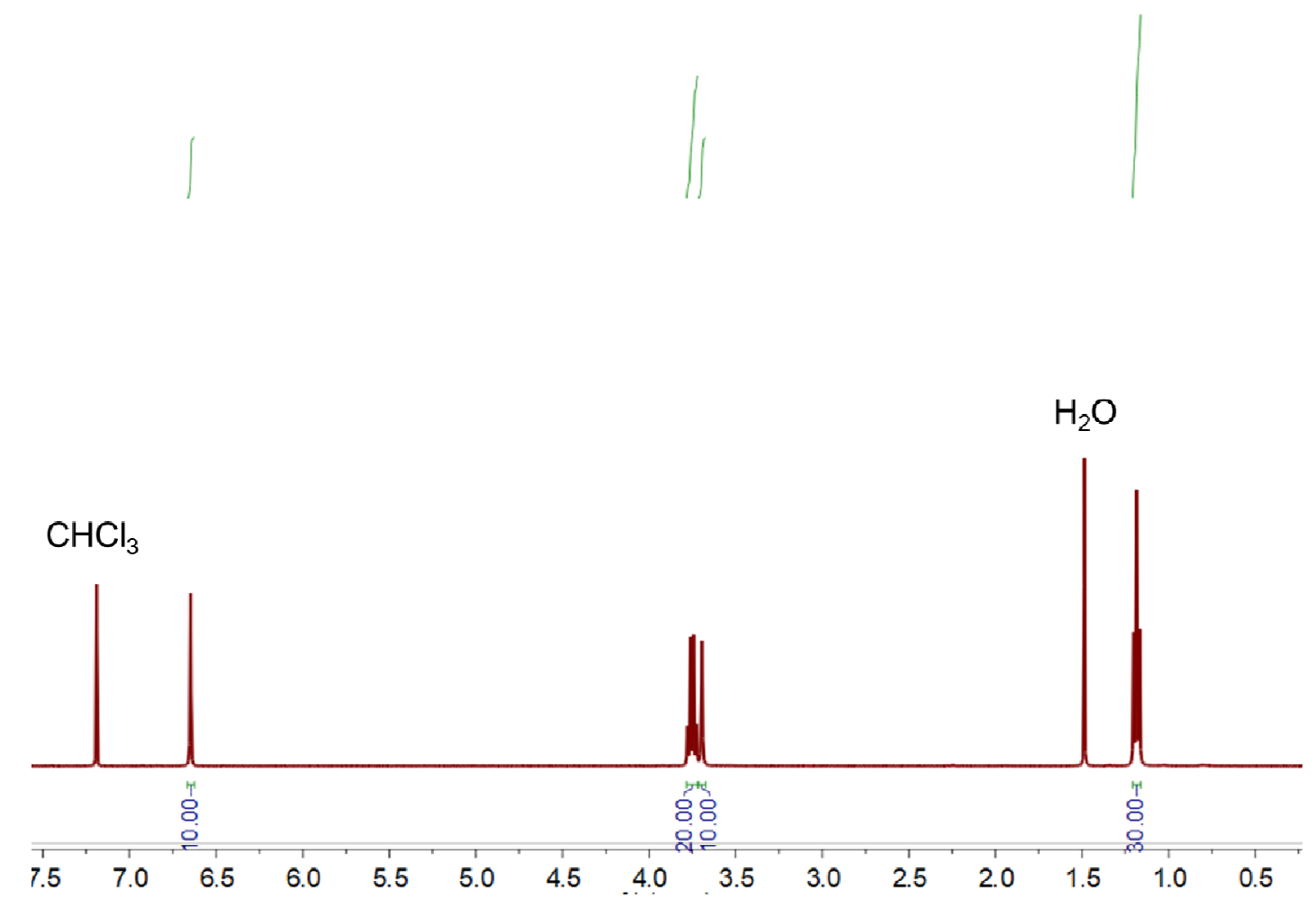

Figure S9. ${ }^{1} \mathrm{H}$ NMR spectrum (400 MHz, chloroform- $d$, $298 \mathrm{~K}$ ) of EtP5 $\alpha$ after sorption of OCT vapor for $24 \mathrm{~h}$. 


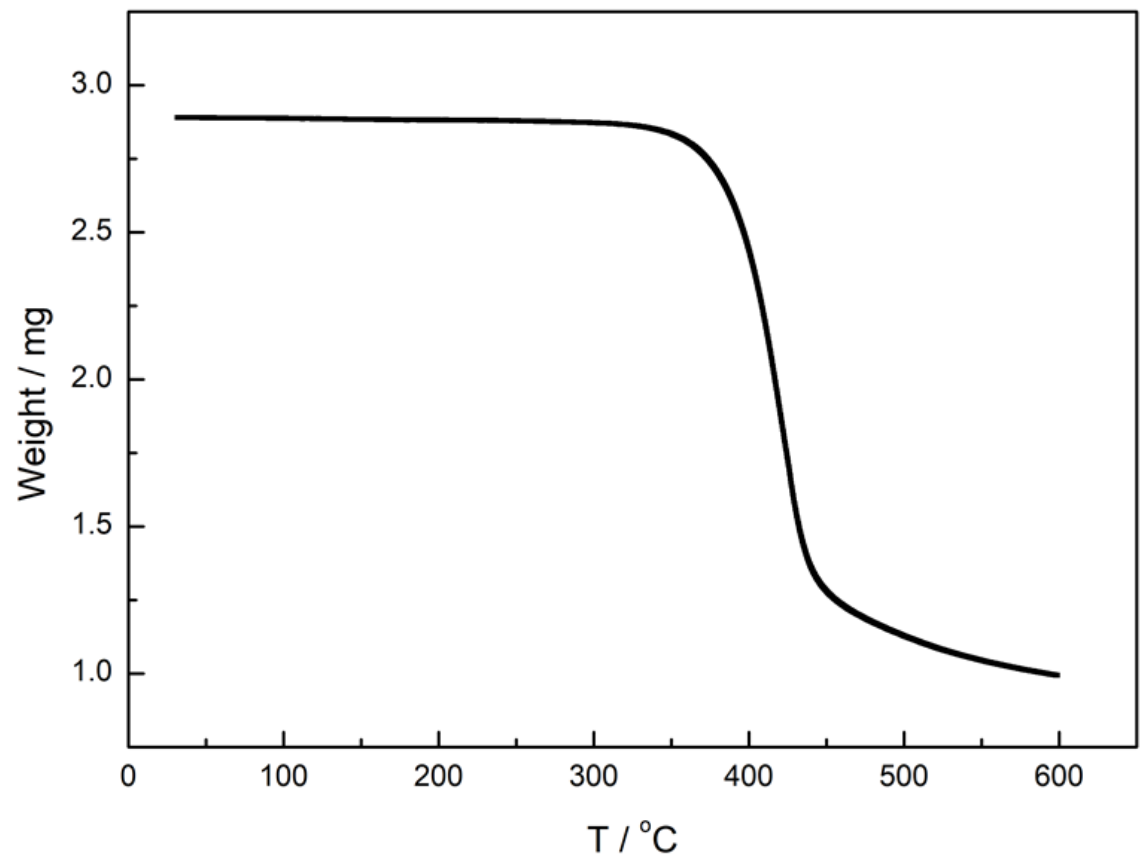

Figure S10. Thermogravimetric analysis of EtP5 $\alpha$ after sorption of OCT vapor for $24 \mathrm{~h}$.

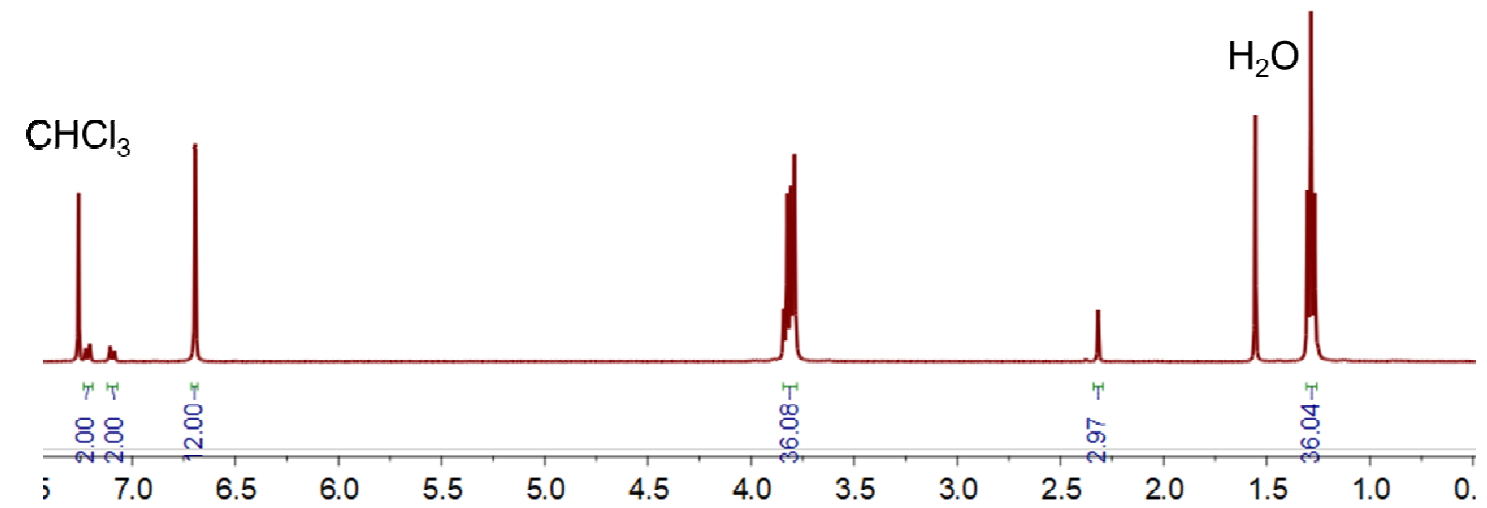

Figure S11. ${ }^{1} \mathrm{H}$ NMR spectrum (400 MHz, chloroform- $d$, $298 \mathrm{~K}$ ) of EtP6 $\beta$ after sorption of PCT vapor for $24 \mathrm{~h}$. 


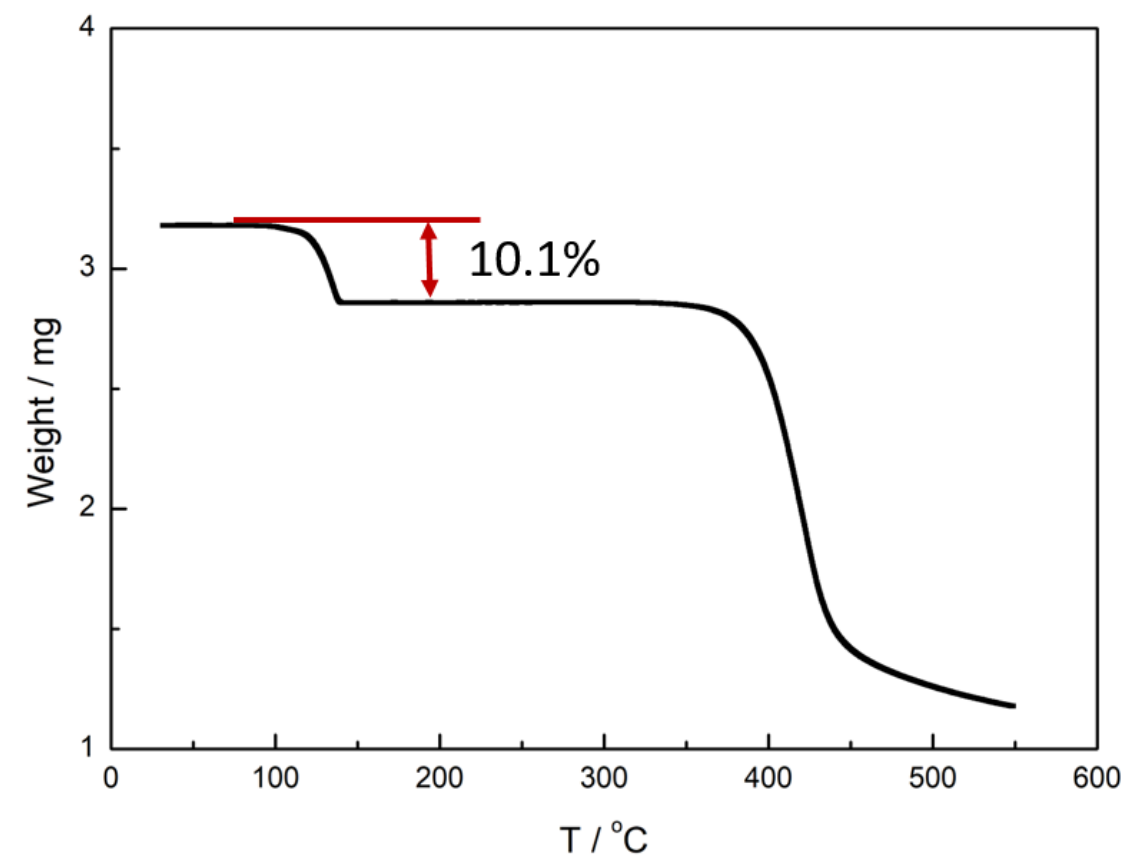

Figure S12. Thermogravimetric analysis of EtP6 $\beta$ after sorption of PCT vapor for $24 \mathrm{~h}$. The weight loss below $150^{\circ} \mathrm{C}$ can be calculated as one PCT molecule per EtP6 molecule.

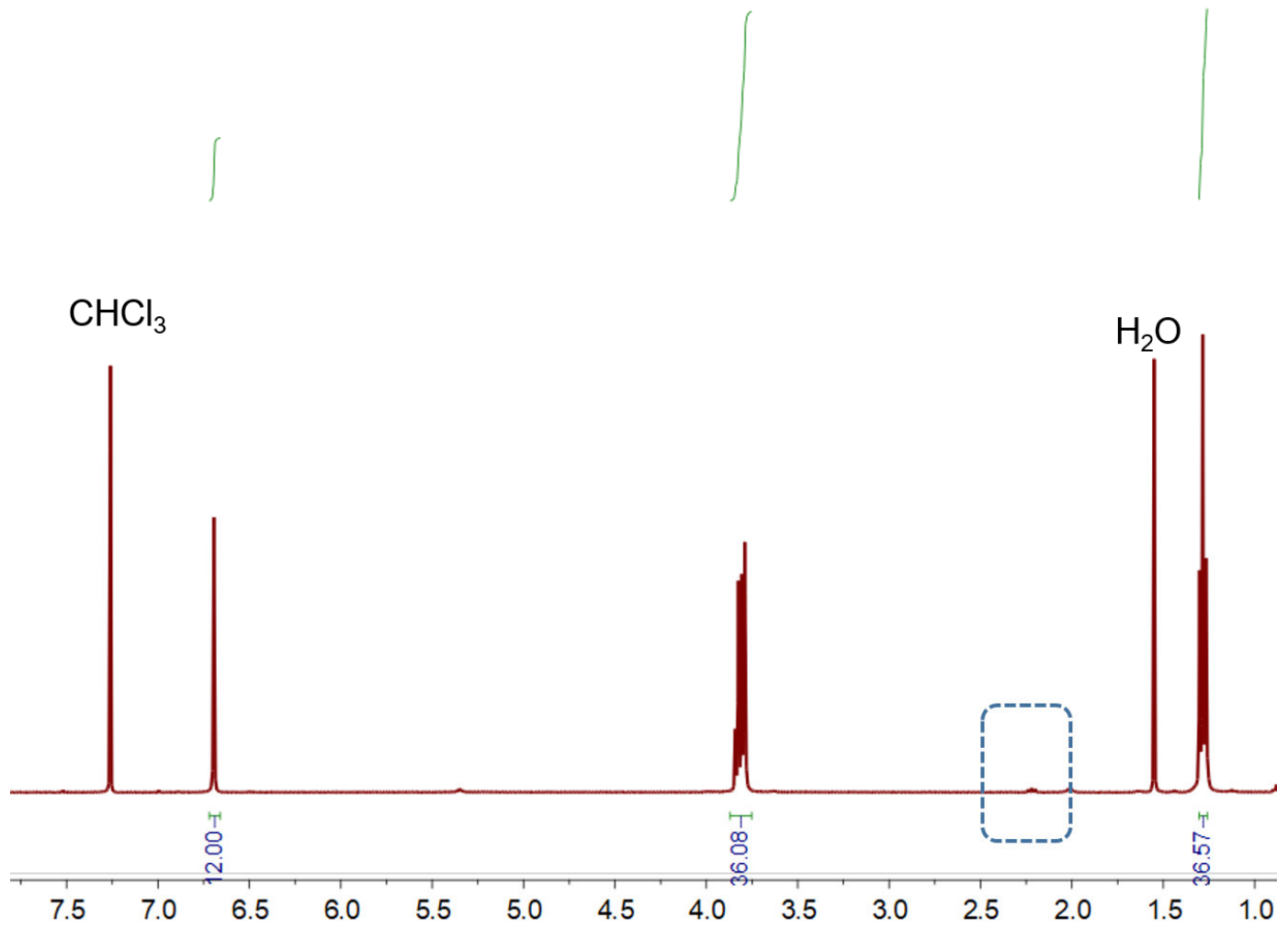

Figure S13. ${ }^{1} \mathrm{H}$ NMR spectrum (400 MHz, chloroform- $d$, $298 \mathrm{~K}$ ) of EtP6 $\beta$ after sorption of OCT vapor for $24 \mathrm{~h}$. A weak signal related to protons on the methyl group of OCT was found, indicating the weak absorption of EtP6 $\beta$ to OCT vapor. 


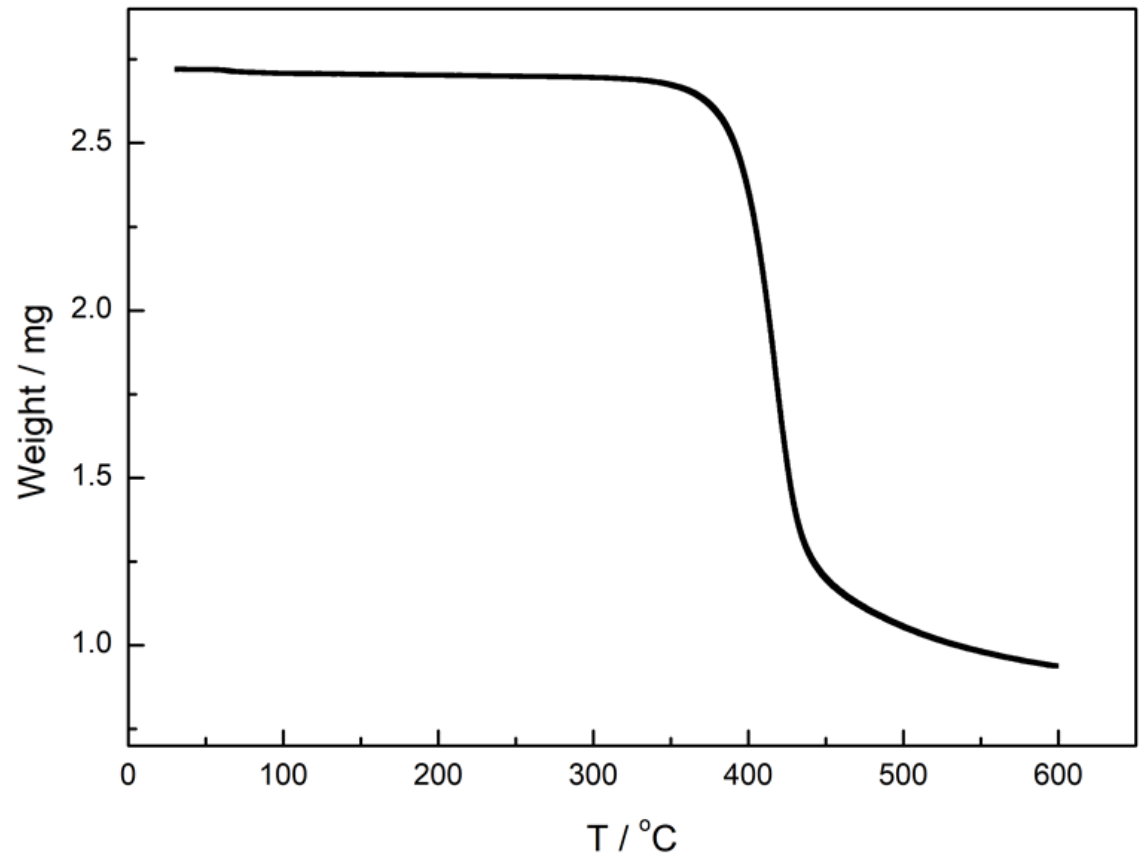

Figure S14. Thermogravimetric analysis of EtP6 $\beta$ after sorption of OCT vapor for $24 \mathrm{~h}$. 


\section{Noncovalent Interactions Analysis in Single Crystal Structures}
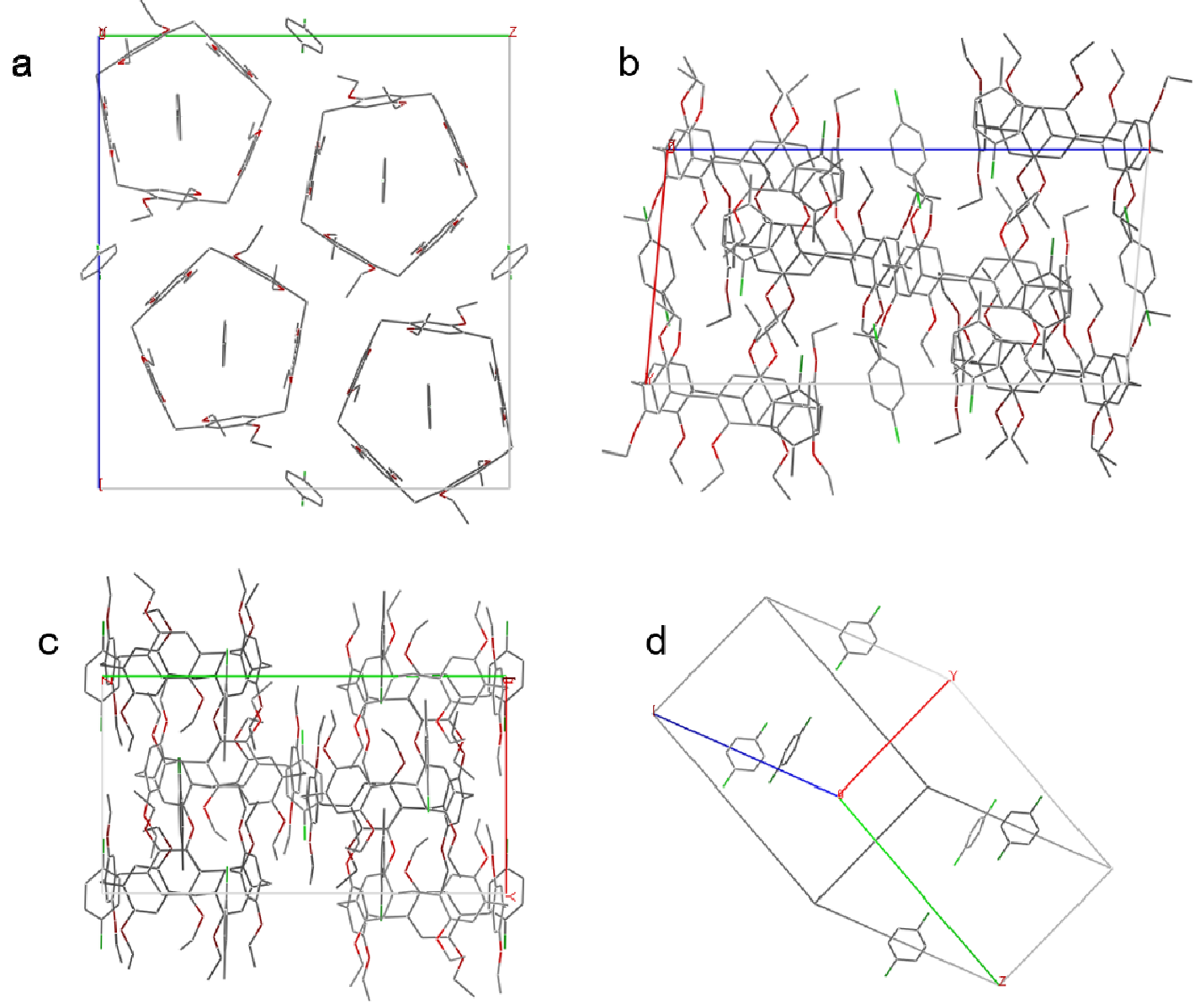

Figure S15. Illustration of PCT-loaded EtP5 lattice: a) along $a$ axis; b) along $b$ axis; c) along $c$ axis; d) PCT molecules at the edge centers and face centers. As shown here, every lattice contains four EtP5 molecules, four PCT molecules in the cavities of EtP5 molecules, two PCT molecules (shared with another lattice) at the face centers, and four PCT molecules (shared with three other lattices) at the edge centers. Therefore, we can know that every lattice contains four EtP5 molecules and six PCT molecules. The crystal structure formula can be termed as (PCT) $)_{3} @(\text { EtP5 })_{2}$.

The $\mathrm{CH} \cdots \pi$ interactions were determined according to a reported method. ${ }^{\mathrm{S}}{ }^{\mathrm{S} 5}$ (a) Case one: $\mathrm{H}$ is above the aromatic ring and the $\mathrm{H}-\pi$-plane distance is shorter than $3.05 \AA$. (b) Case two: $\mathrm{H}$ is not above the aromatic ring, the angle $\mathrm{H}-\mathrm{C} \cdots \mathrm{C}^{1}$, where $\mathrm{C}^{1}$ is the nearest $\mathrm{sp}^{2}$-carbon to $\mathrm{H}$, is smaller than $60^{\circ}$, the dihedral angle defined by the aromatic ring and $\mathrm{H}^{\cdots} \mathrm{C}^{1} \mathrm{C}^{2} \cdots \mathrm{I}$ planes, where $\mathrm{C}^{2}$ is the second nearest $\mathrm{sp}^{2}$-carbon to $\mathrm{H}$ and $\mathrm{I}$ is the projection of $\mathrm{H}$ on the aromatic ring, is between $90^{\circ}$ and $130^{\circ}$ and the $\mathrm{H}-$ line $\mathrm{C}^{1} \mathrm{C}^{2}$ distance is shorter than $3.05 \AA$. (c) Case three: $\mathrm{H}$ is not above the aromatic ring, the angle $\mathrm{H}-\mathrm{C} \cdots \mathrm{C}^{1}$ is smaller than $60^{\circ}$, the angle $\mathrm{H}^{\cdots} \mathrm{C}^{1} \cdots \mathrm{I}$ is between $50^{\circ}$ and $90^{\circ}$ and the $\mathrm{H}-\mathrm{C}^{1}$ distance is shorter than 3.05 $\AA$. 


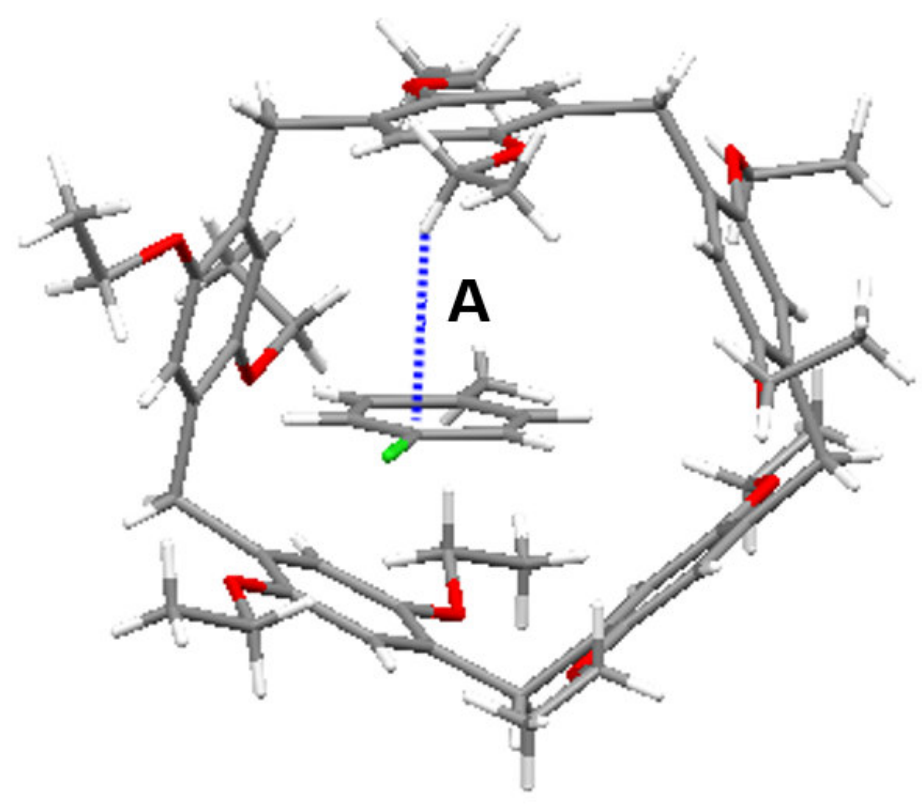

Figure S16. Illustration of a $\mathrm{CH} \cdots \pi$ interaction between an ethyl group on EtP5 and the benzene ring on PCT. The $\mathrm{CH}^{\cdots} \pi \pi$ interaction accords with Case one. $\mathrm{H}-\pi$-plane distance: $\mathbf{A}=2.867 \AA$.

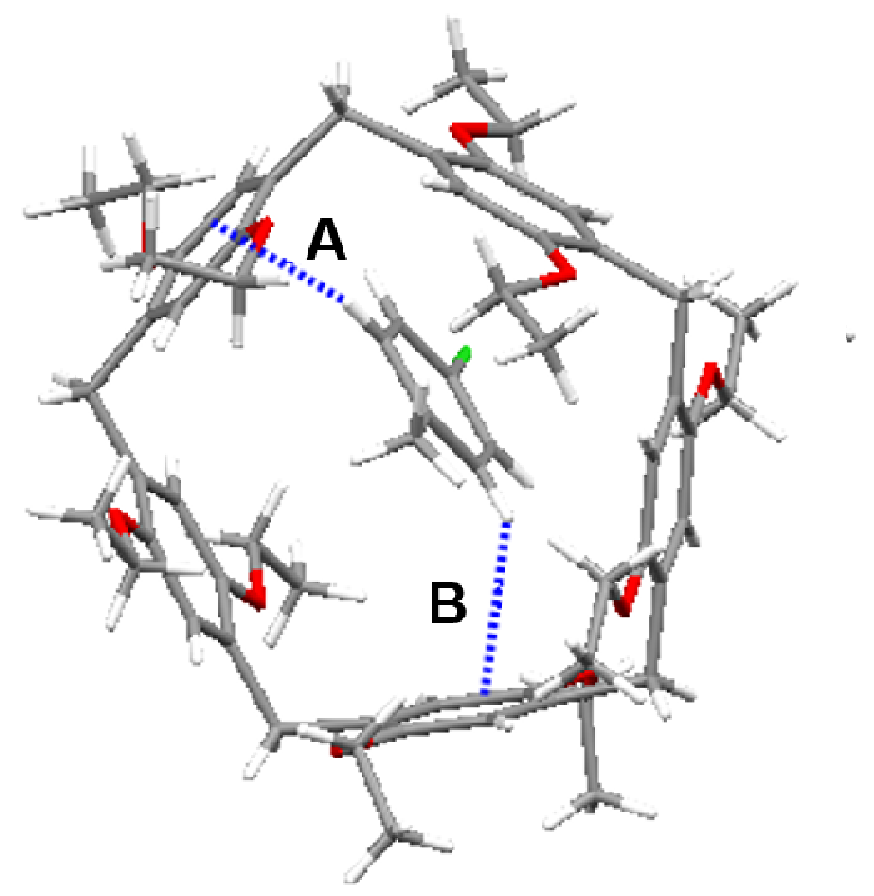

Figure S17. Illustration of $\mathrm{CH}^{\cdots} \pi$ interactions between two $\mathrm{H}$ atoms on the benzene ring of PCT and two coordinated benzene rings on EtP5. These $\mathrm{CH}^{\cdots} \pi$ interactions accord with Case two. Angles $\mathrm{H}-\mathrm{C} \cdots \mathrm{C}^{1}$ $\left(\mathrm{C}^{1}\right.$ is the nearest sp2-carbon to $\left.\mathrm{H}\right): 2.42^{\circ}, 16.74^{\circ}$; dihedral angles defined by the aromatic ring and $\mathrm{H} \cdots \mathrm{C}^{1} \mathrm{C}^{2} \cdots \mathrm{I}\left(\mathrm{C}^{2}\right.$ is the second nearest $\mathrm{sp}^{2}$-carbons to $\mathrm{H}$ and $\mathrm{I}$ is the projection of $\mathrm{H}$ on the aromatic ring) planes: $105.89^{\circ}, 113.50^{\circ}$; $\mathrm{H}-$ line $\mathrm{C}^{1} \mathrm{C}^{2}$ distances: $\mathbf{A}=2.636 \AA, \mathbf{B}=2.746 \AA$. 


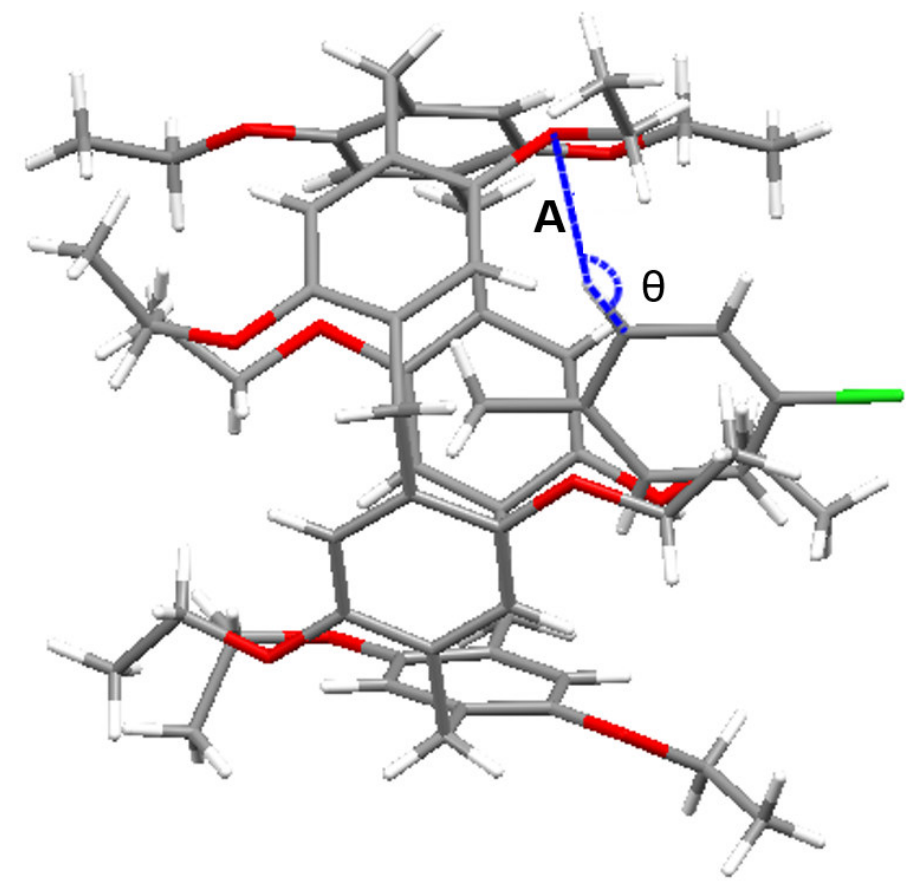

Figure S18. Illustration of the hydrogen binding between an $\mathrm{O}$ atom on EtP5 and an aromatic $\mathrm{H}$ atom on PCT. H $\cdots \mathrm{O}$ distance: $\mathbf{A}=2.652 \AA ; \mathrm{C}-\mathrm{H} \cdots \mathrm{O}$ angle: $\theta=153.95^{\circ}$.

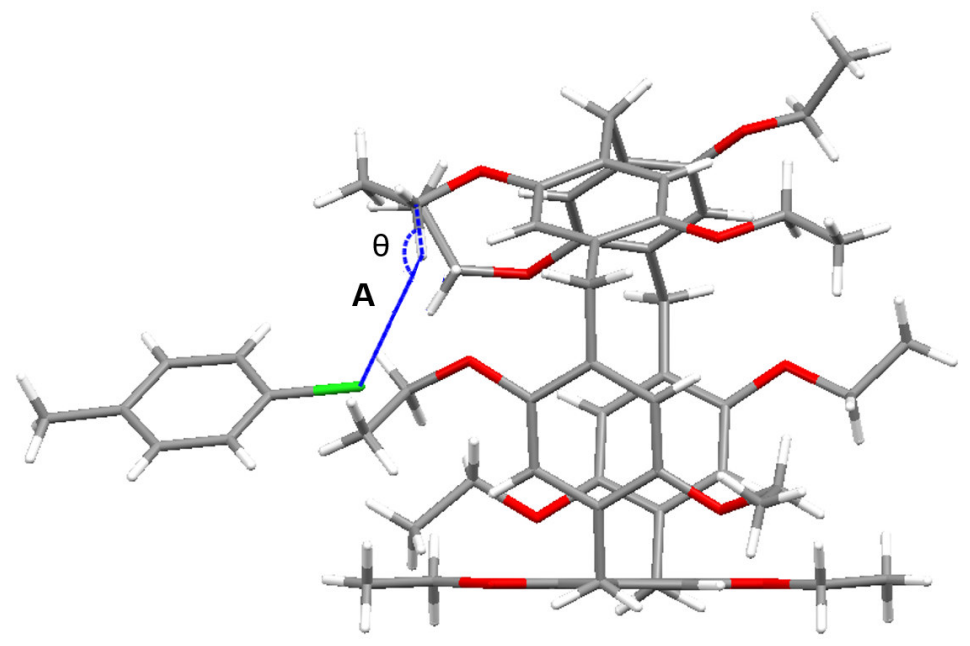

Figure S19. Illustration of $\mathrm{CH} \cdots \mathrm{Cl}$ interaction between ethyl on EtP5 and $\mathrm{Cl}$ on PCT. $\mathrm{H} \cdots \mathrm{Cl}$ distance: A $=3.147 \AA ; \mathrm{C}-\mathrm{H} \cdots \mathrm{Cl}$ angle $=137.73^{\circ}$. 


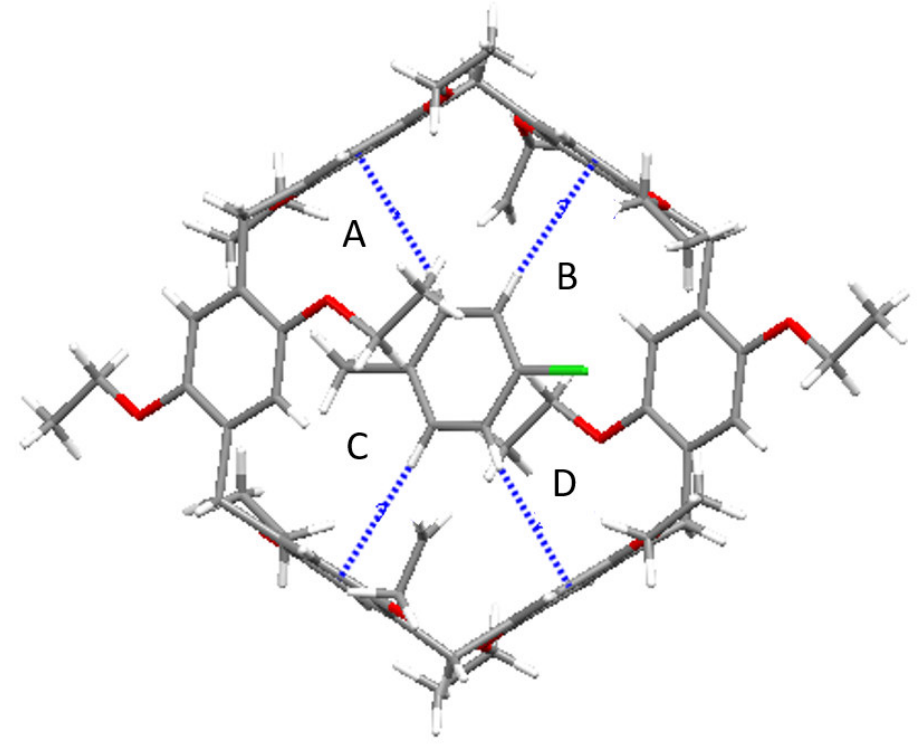

Figure S20. Illustration of edge-to-face $\pi$-stacking interactions between EtP6 and PCT. H- $\pi$-plane distances: $\mathbf{A}=2.821 \AA, \mathbf{B}=2.834 \AA, \mathbf{C}=2.788 \AA, \mathbf{D}=2.838 \AA$.

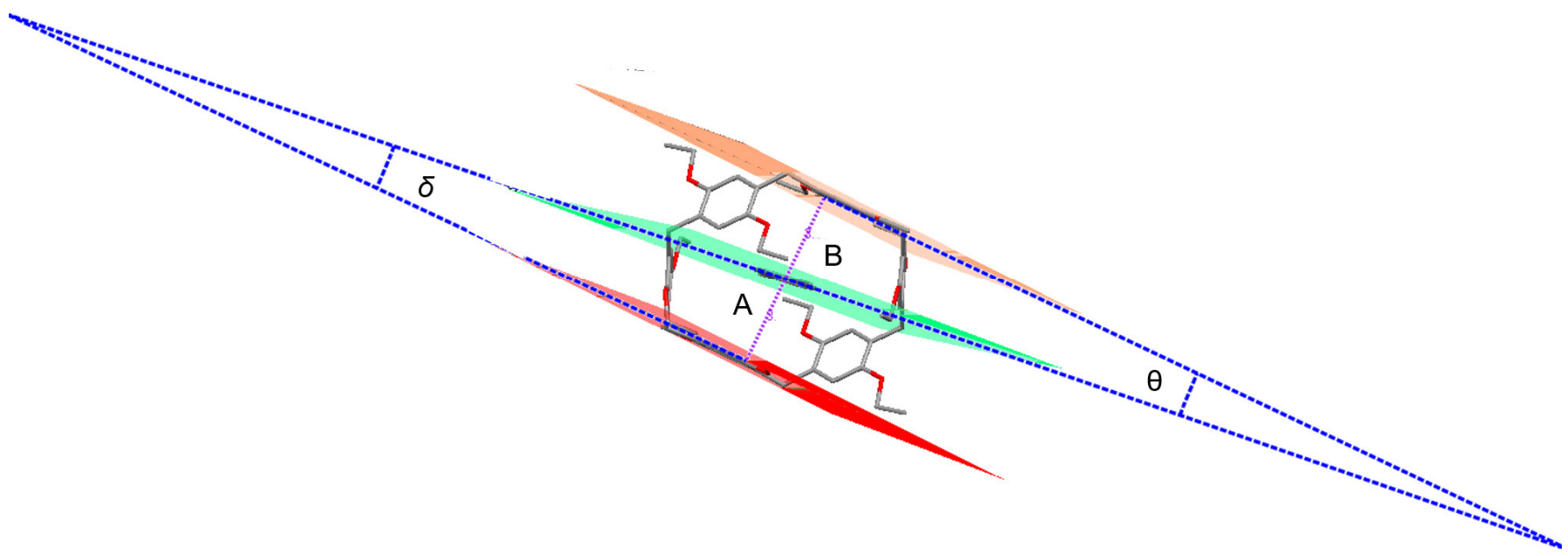

Figure S21. Illustration of face-to-face $\pi$-stacking interactions between EtP6 and PCT. Centroid-centroid distances: $\mathbf{A}=3.937 \AA, \mathbf{B}=3.923 \AA$; dihedral angles: $\theta=6.27^{\circ}, \delta=6.30^{\circ}$. 
7. Uptake Study of $p$-Chlorotoluene in EtP5 $\alpha$ and EtP6 $\beta$ upon Absorption of p-Chlorotoluene/o-Chlorotoluene Mixtures with Various $p$-Chlorotoluene Fractions

For each PCT/OCT mixture vapor-phase absorption experiment, an open $5 \mathrm{~mL}$ vial containing $4 \mathrm{mg}$ of guest-free EtP5 $\alpha$ or EtP6 $\beta$ adsorbent was placed in a sealed $20 \mathrm{~mL}$ vial containing $1 \mathrm{~mL}$ of a PCT/OCT mixture with varying PCT fraction. The temperature was maintained at $298 \mathrm{~K}$ or $333 \mathrm{~K}$. The crystals after absorption were heated at $50{ }^{\circ} \mathrm{C}$ under vacuum for $30 \mathrm{~min}$ to remove the monochlorotoluene molecules adsorbed on the crystal surfaces. Uptake of PCT in EtP5 $\alpha$ or EtP6 $\beta$ was measured by completely dissolving the crystals and measuring the molar ratio of PCT to EtP6 or EtP5 by ${ }^{1} \mathrm{H}$ NMR after sorption of the mixture vapor for 12 hour.

As shown in the Figures S22-S24, EtP5 $\alpha$ uptakes PCT when the fraction of PCT is 0.24 at $298 \mathrm{~K}$. And the starting fraction of uptaking PCT changed to 0.34 at $333 \mathrm{~K}$. This was because the PCT absorption is an exothermic process, and the increase of temperature is infavorable for the absorption, which can be explained by Le Chatelier's principle. ${ }^{\mathrm{S} 6}$

However, a similar phenomenon was not observed for the adsorption of PCT into EtP6 due to the strong complexation between PCT and EtP6 (Figures S25-S27). Besides, a weak signal of protons on OCT was observed when the fraction of OCT was $>0.80$. There are two reasons for this phenomenon. At first, the larger cavity of EtP6 can also accommodate OCT, which was proved by the OCT-loaded EtP6 single crystal structure (Figure 3d). Secondly, when the fraction of OCT was $>0.80$, EtP6 crystals were also surrounded by OCT molecules.

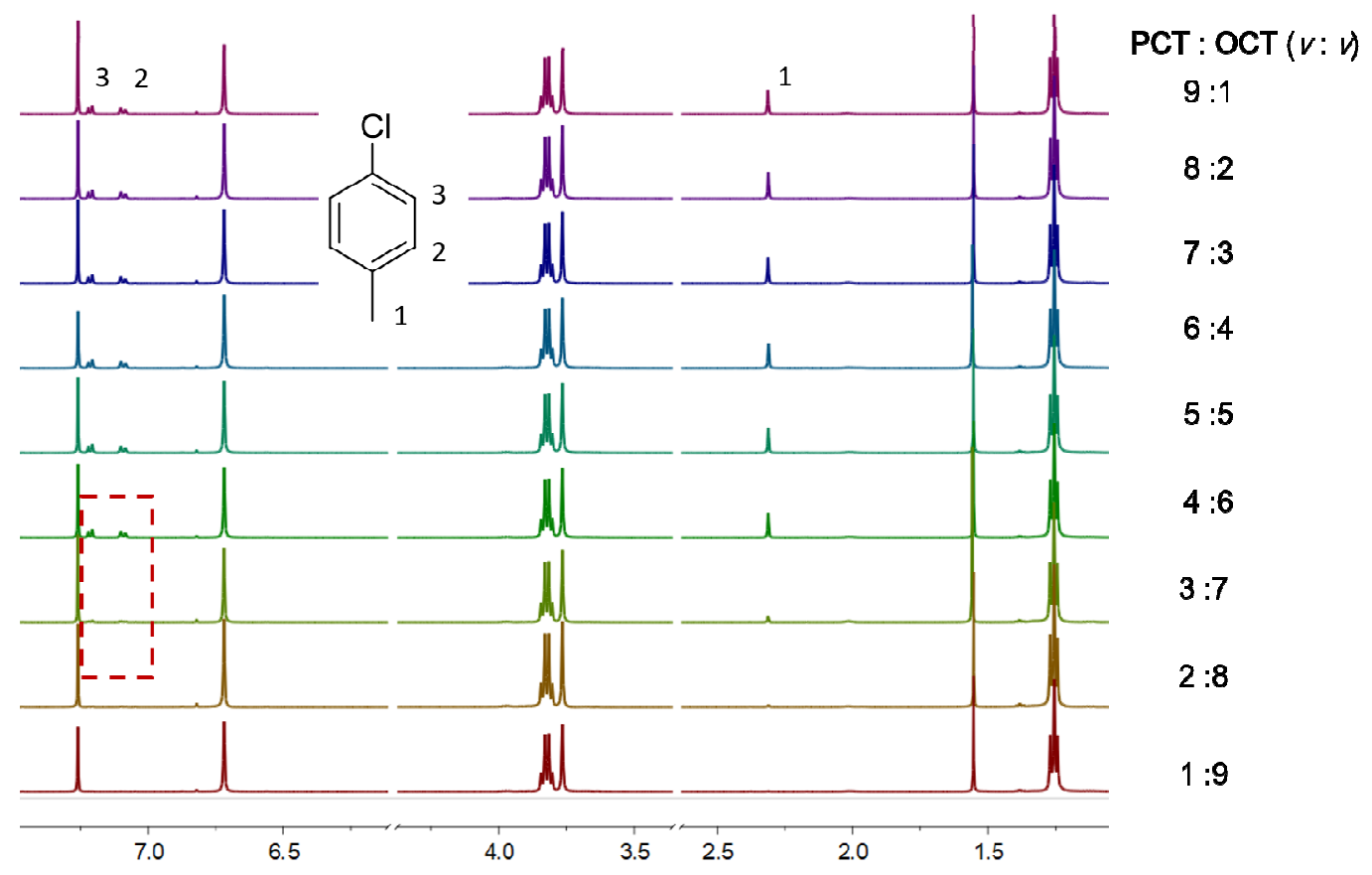

Figure S22. ${ }^{1} \mathrm{H}$ NMR spectra (400 MHz, chloroform- $d$, $298 \mathrm{~K}$ ) of EtP5 $\alpha$ after sorption of the vapors of PCT/OCT mixtures with various PCT fractions for $12 \mathrm{~h}$ at $298 \mathrm{~K}$. 


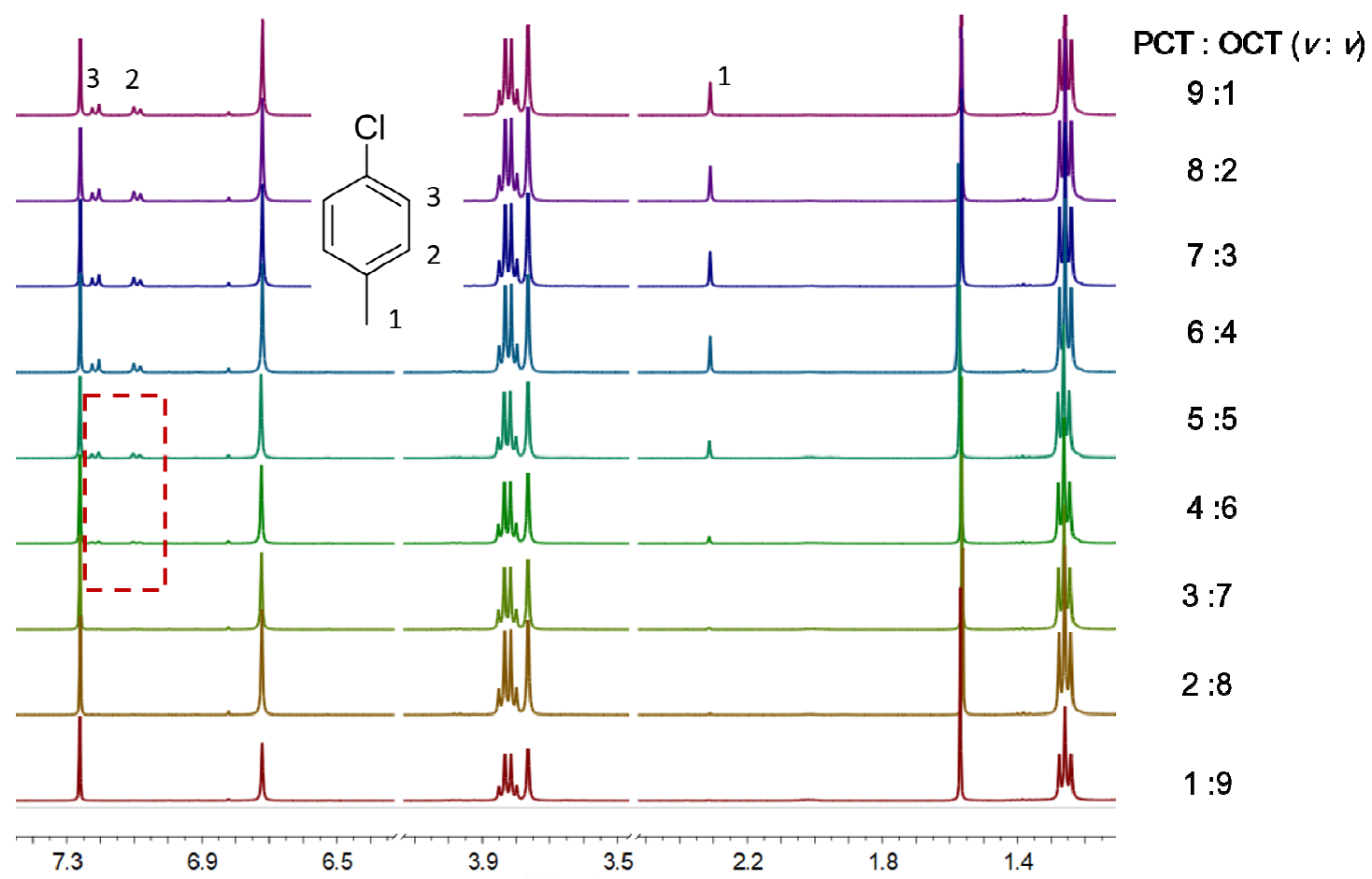

Figure S23. ${ }^{1} \mathrm{H}$ NMR spectra (400 MHz, chloroform- $d$, $298 \mathrm{~K}$ ) of EtP5 $\alpha$ after sorption of the vapors of PCT/OCT mixtures with various PCT fractions for $12 \mathrm{~h}$ at $333 \mathrm{~K}$.

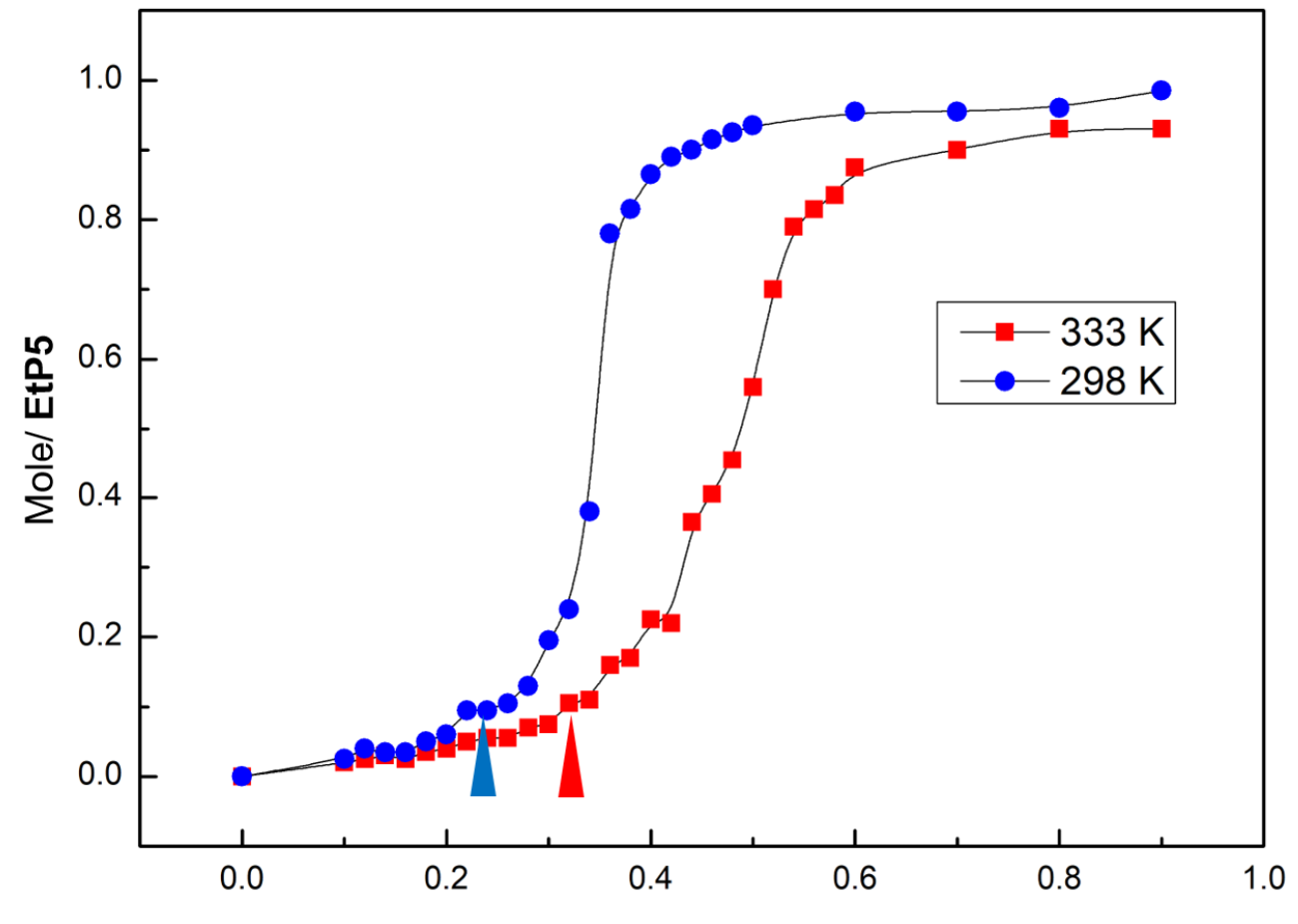

Fraction of PCT in PCT/OCT Mixtures

Figure S24. Changes of the PCT uptake in EtP5 $\alpha$ after sorption of the vapors of PCT/OCT mixtures with various PCT fractions for $12 \mathrm{~h}$ at different temperatures. 


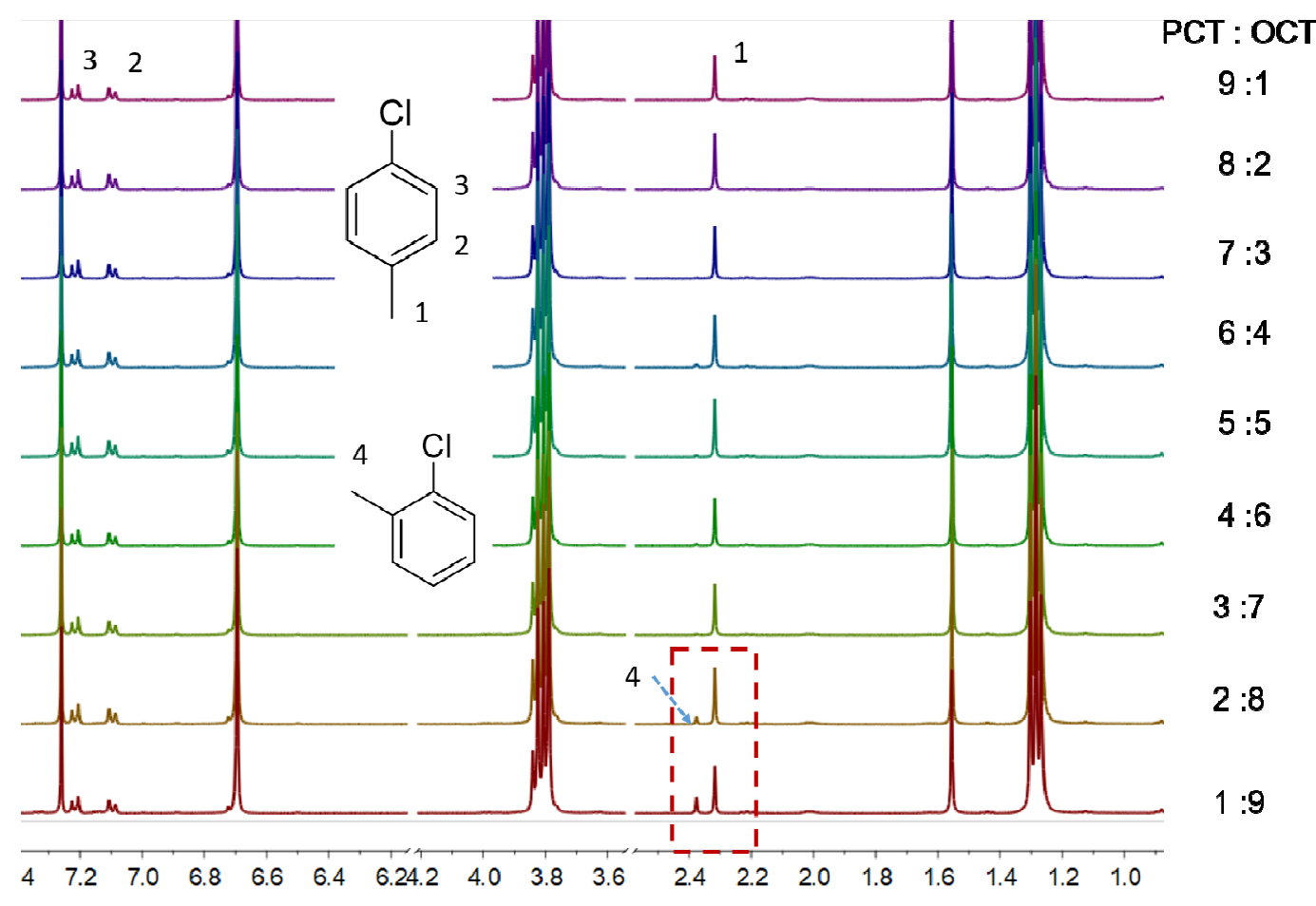

Figure S25. ${ }^{1} \mathrm{H}$ NMR spectra (400 MHz, chloroform- $d$, $298 \mathrm{~K}$ ) of $\mathbf{E t P 6} \beta$ after sorption of the vapors of PCT/OCT mixtures with various PCT fractions for $12 \mathrm{~h}$ at $298 \mathrm{~K}$.

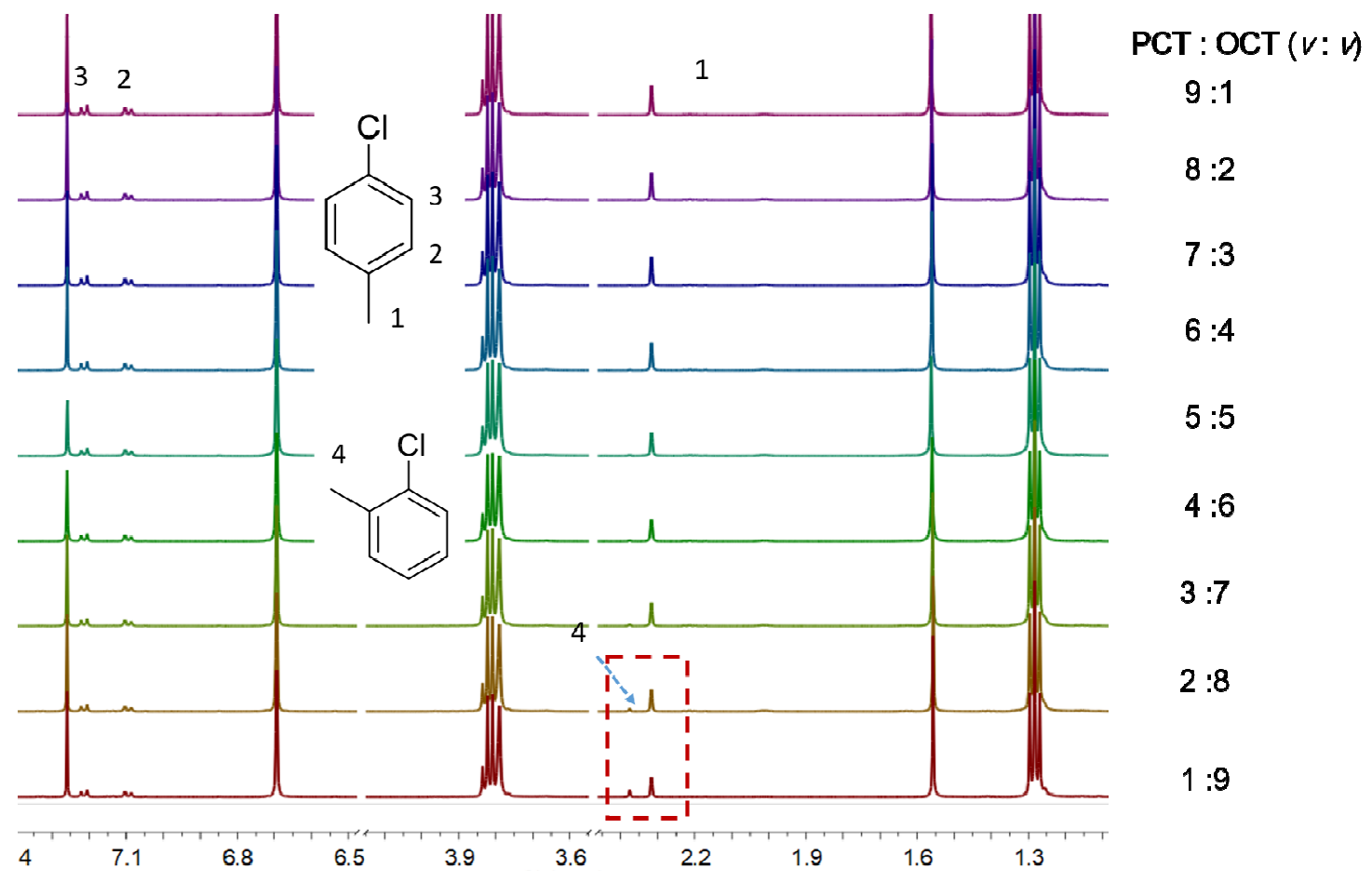

Figure S26. ${ }^{1} \mathrm{H}$ NMR spectra (400 MHz, chloroform- $d$, $298 \mathrm{~K}$ ) of EtP6 $\beta$ after absorption to the vapors of PCT/OCT mixtures with various PCT fractions for $12 \mathrm{~h}$ at $333 \mathrm{~K}$. 


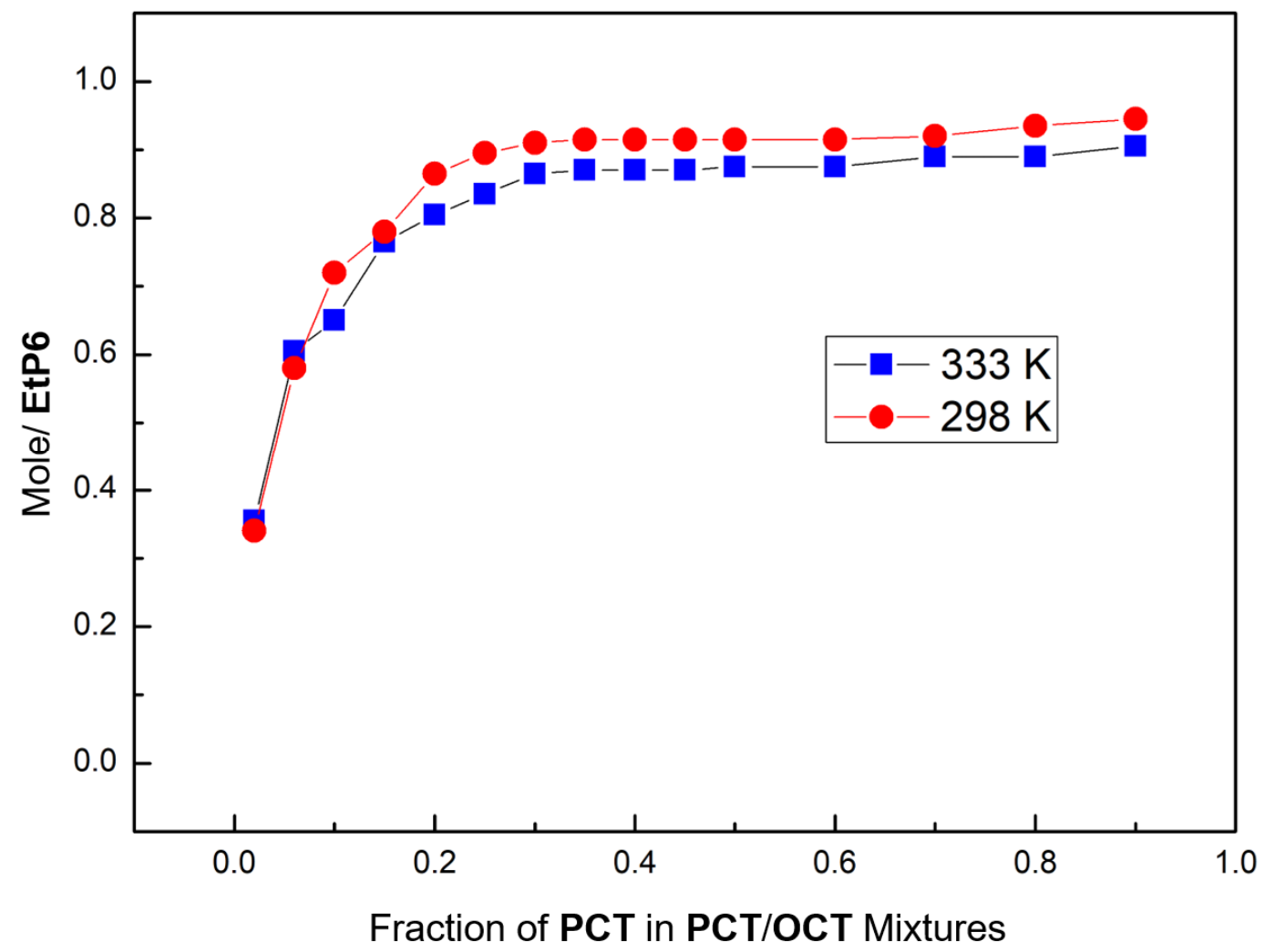

Figure S27. Changes of the PCT uptake in EtP6 $\beta$ after sorption of the vapors of PCT/OCT mixtures with various PCT fractions for $12 \mathrm{~h}$ at different temperatures. 


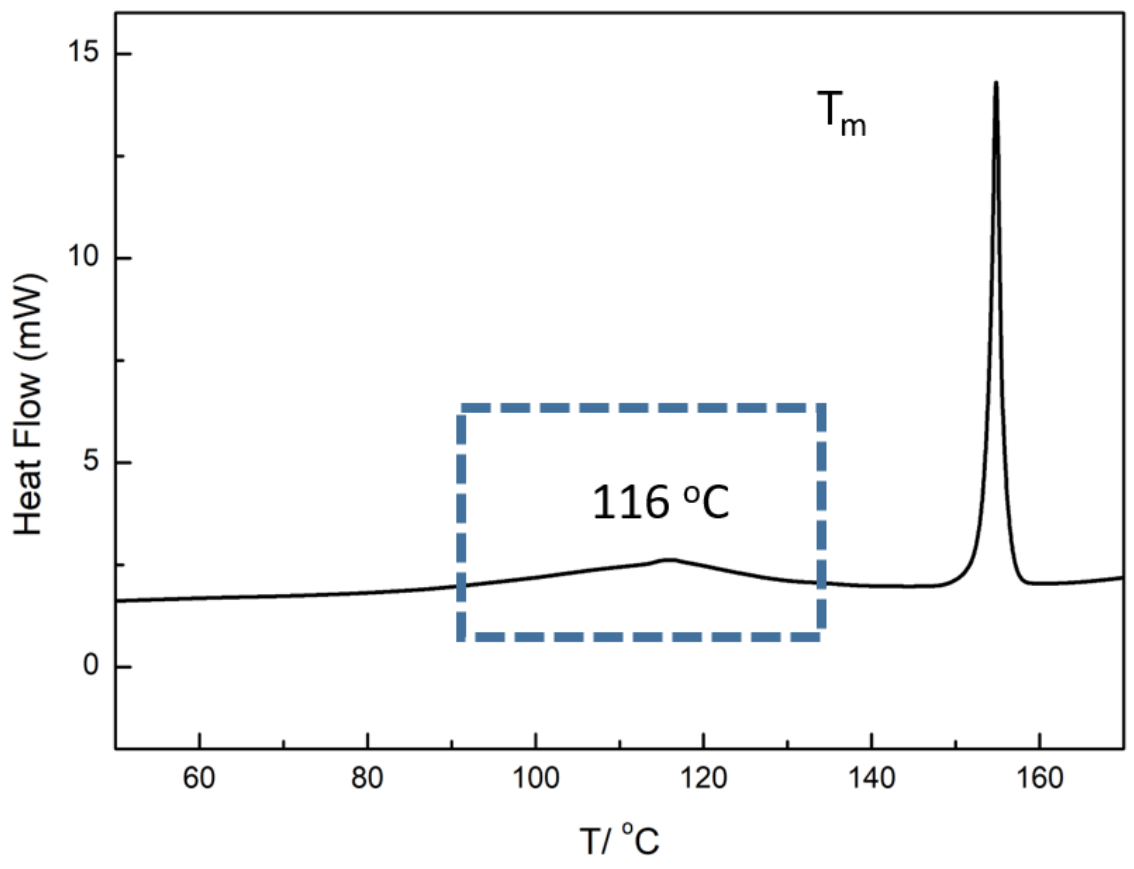

Figure S28. DSC plot of PCT-loaded EtP5 $\alpha$.

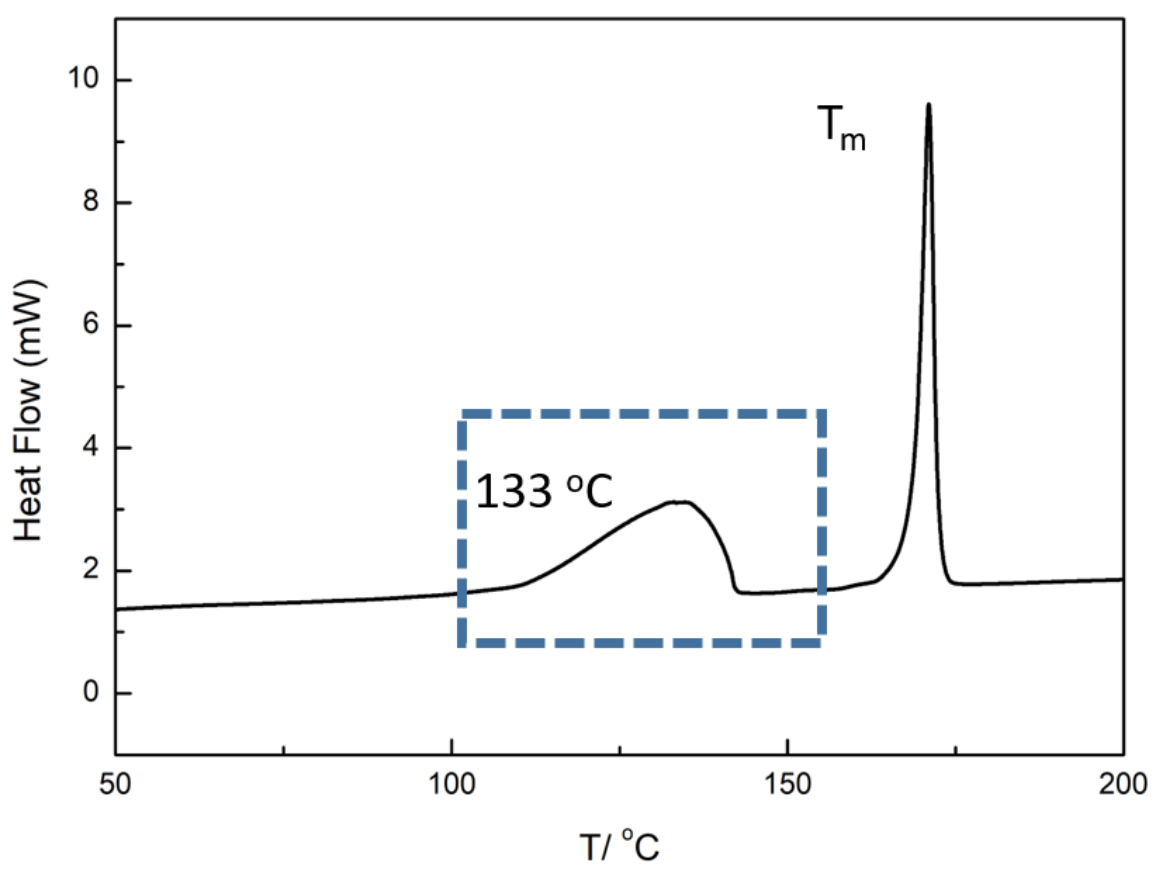

Figure S29. DSC plot of PCT-loaded EtP6 $\beta$. 


\subsection{Separation of PCT from a PCT/OCT Equimolar Mixture by EtP5 $\alpha$ and EtP6 $\beta$}

An open $5 \mathrm{~mL}$ vial containing $20 \mathrm{mg}$ of guest-free $\mathbf{E t P 5} \alpha$ or $\mathbf{E t P 6} \beta$ adsorbent was placed in a sealed $20 \mathrm{~mL}$ vial containing $1 \mathrm{~mL}$ of a PCT/OCT equimolar mixture.

Time-dependent EtP5 $\alpha$ or EtP6 $\beta$ solid-vapor sorption plots were measured by completely dissolving the crystals and measuring the molar ratio of PCT or OCT to EtP6 or EtP5 every 4 hours by ${ }^{1} \mathrm{H}$ NMR spectroscopy. Thermogravimetric analysis experiments were performed using $\mathbf{E t P 5} \alpha$ or $\mathbf{E t P 6} \beta$ after absorption of the PCT/OCT equimolar mixture vapor for $48 \mathrm{~h}$. The relative uptakes of PCT and OCT in EtP5 $\alpha$ or EtP6 $\beta$ were measured by heating to release the adsorbed vapor and detecting the relative amounts of monochlorotoluene isomers in the released vapor using gas chromatography. Before measurements, the crystals were heated at $50{ }^{\circ} \mathrm{C}$ under vacuum for $30 \mathrm{~min}$ to remove the surface-physically adsorbed monochlorotoluene molecules.

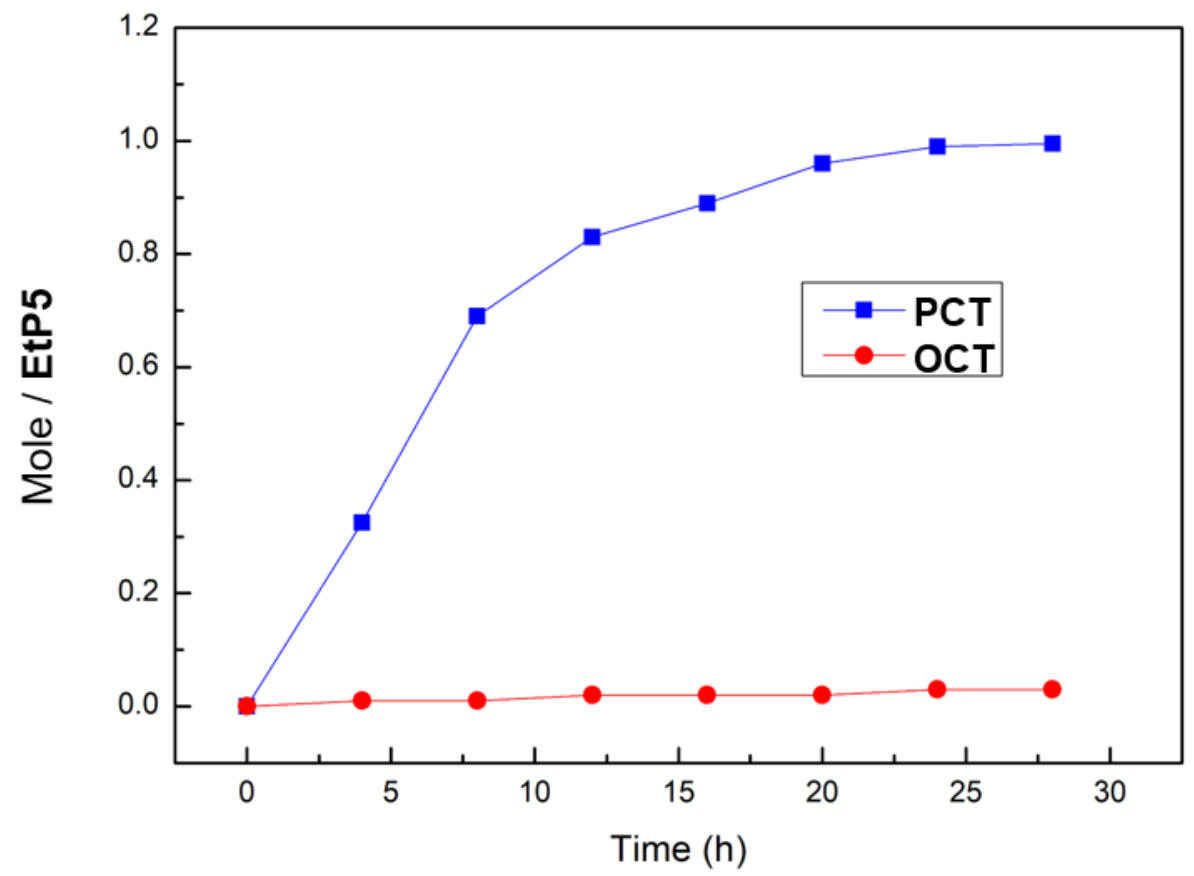

Figure S30. Time-dependent EtP5 $\alpha$ solid-vapor sorption plot for a PCT/OCT equimolar mixture vapor. 


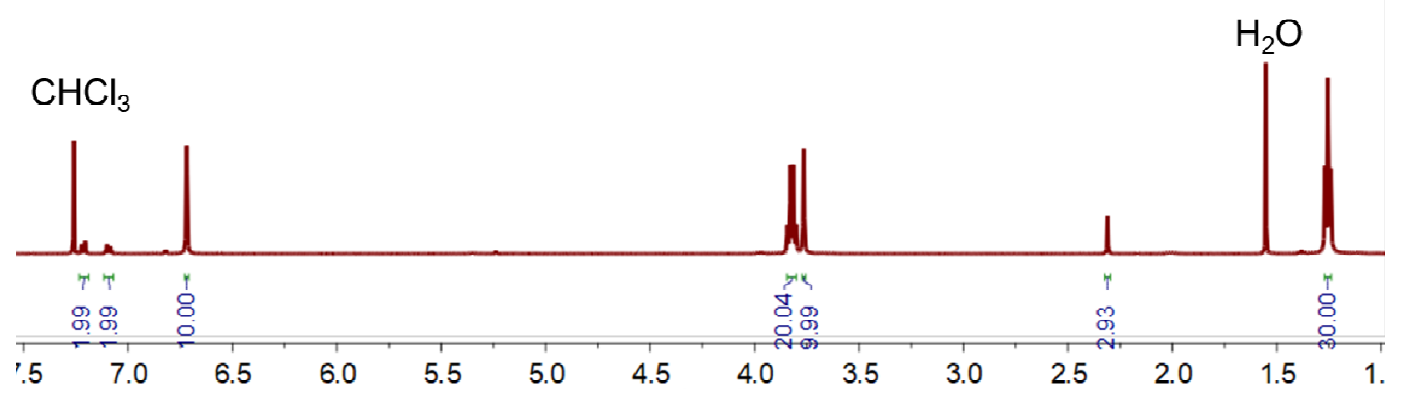

Figure S31. ${ }^{1} \mathrm{H}$ NMR spectrum (400 MHz, chloroform- $d$, $298 \mathrm{~K}$ ) of EtP5 $\alpha$ after sorption of the PCT/OCT equimolar mixture vapor for $48 \mathrm{~h}$.

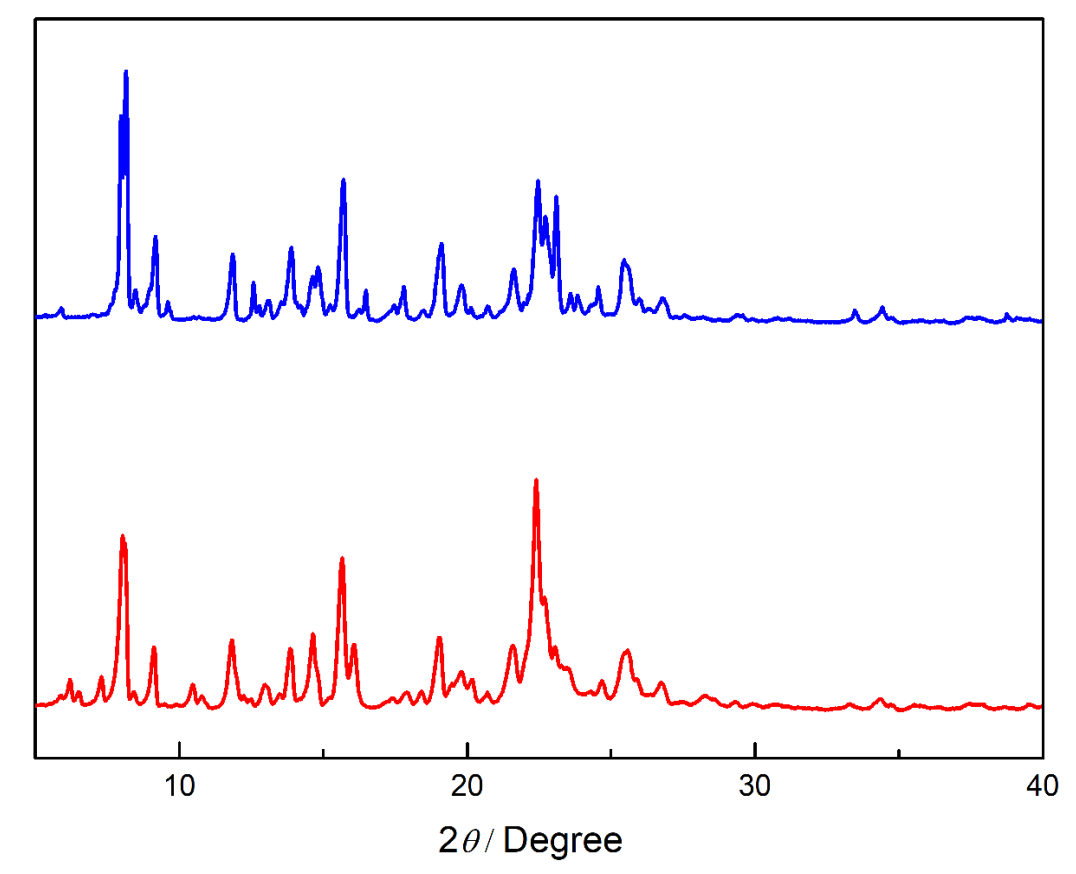

Figure S32. Powder X-ray diffraction patterns of EtP5: (I) EtP5 $\alpha$ upon absorption of PCT vapor for $48 \mathrm{~h}$ (blue); (II) EtP5 $\alpha$ upon absorption of the PCT/OCT equimolar mixture vapor for $48 \mathrm{~h}$ (red). 


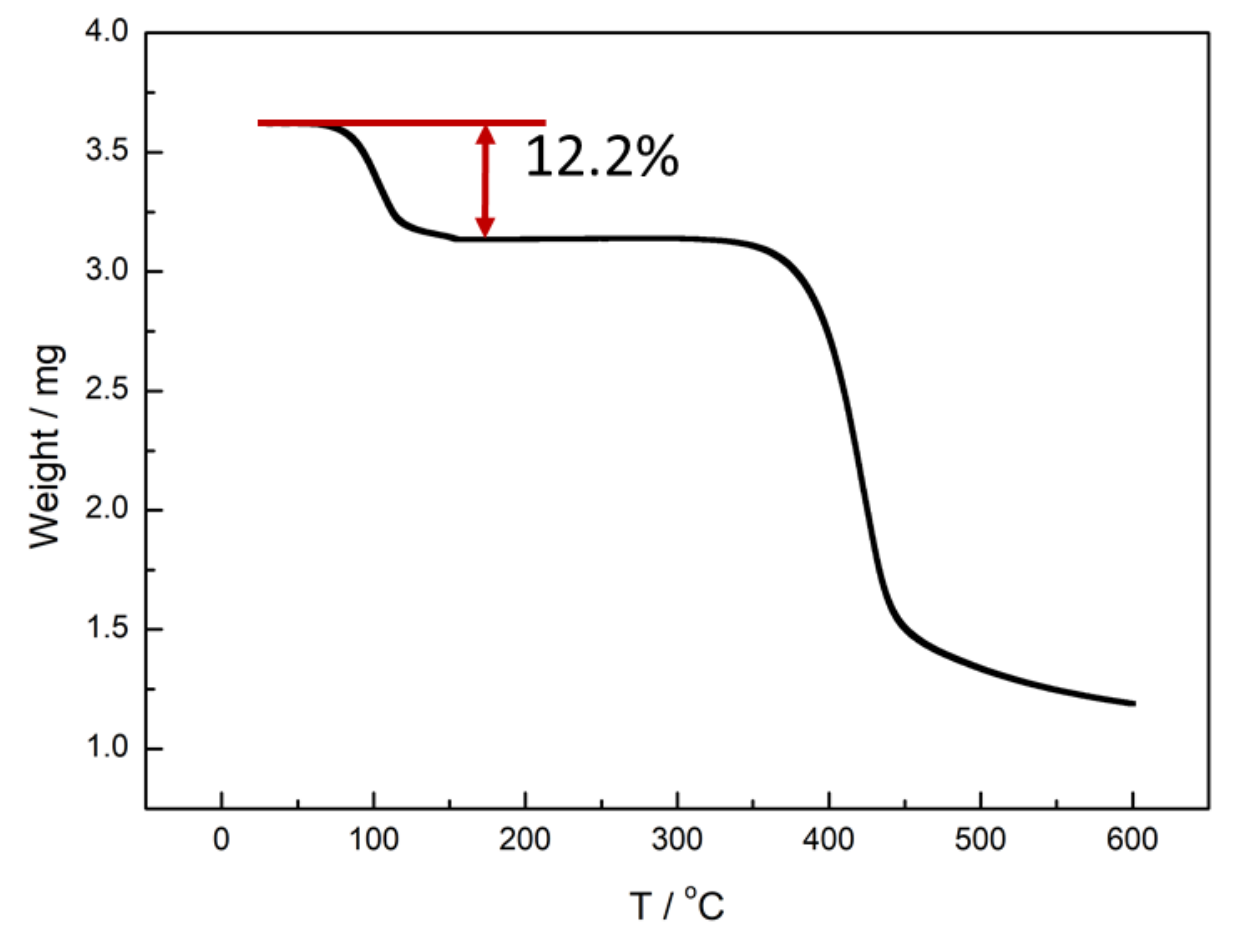

Figure S33. Thermogravimetric analysis of EtP5 $\alpha$ after absorption of the PCT/OCT equimolar mixture vapor for $48 \mathrm{~h}$. The weight loss below $150{ }^{\circ} \mathrm{C}$ can be calculated as one PCT molecule per EtP5 molecule.

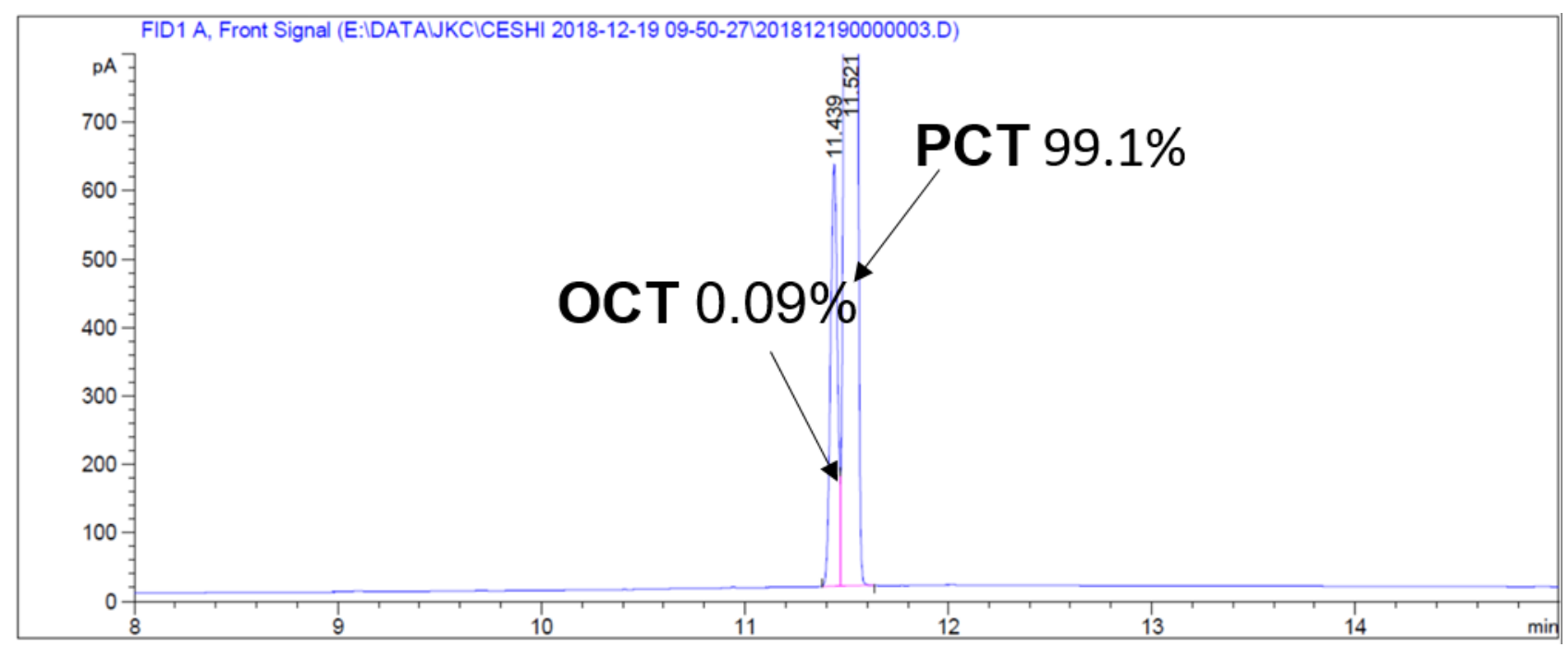

Figure S34. Relative uptakes of PCT and OCT adsorbed in EtP5 $\alpha$ after absorption of the PCT/OCT equimolar mixture vapor for 48 hours using head space gas chromatography. 


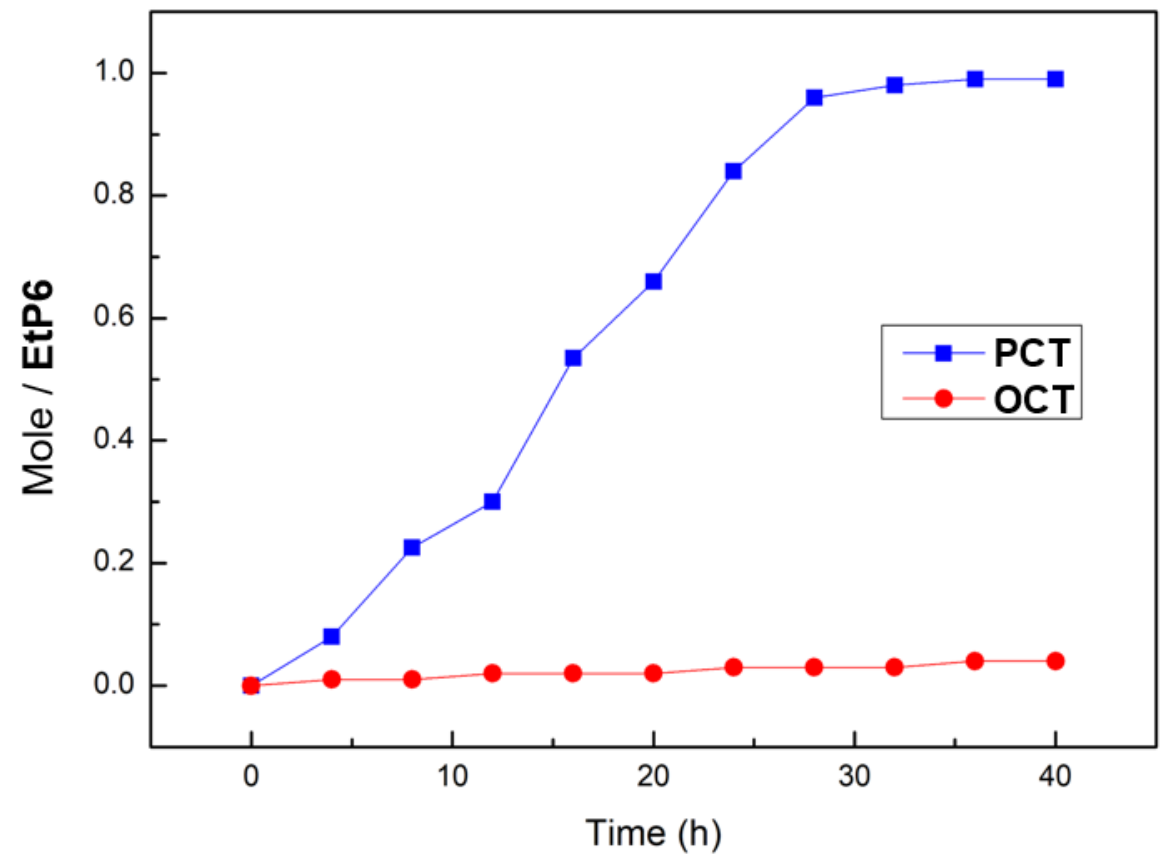

Figure S35. Time-dependent EtP6 $\beta$ solid-vapor sorption plot in EtP6 $\alpha$ for the PCT/OCT equimolar mixture.

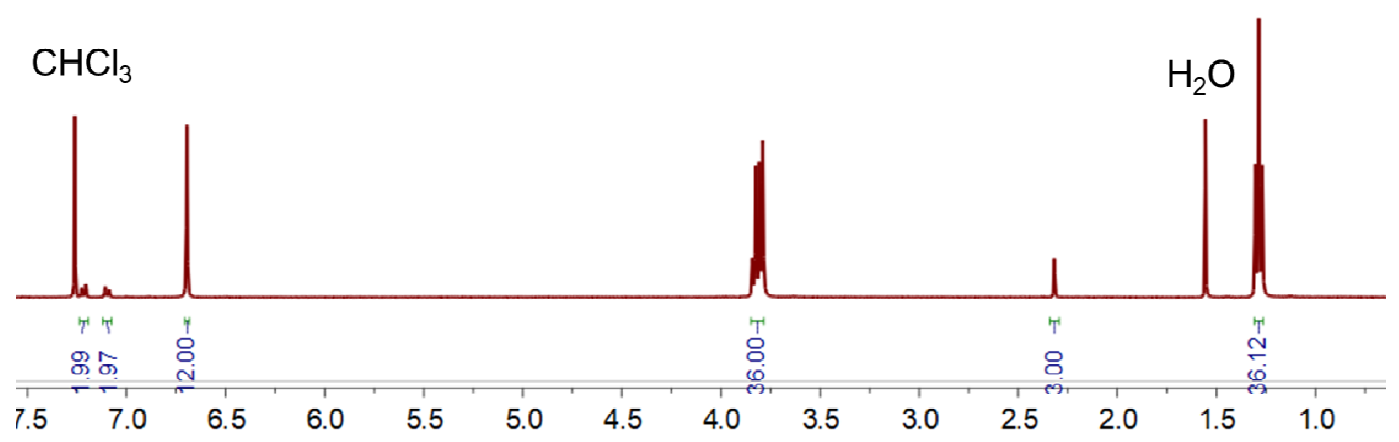

Figure S36. ${ }^{1} \mathrm{H}$ NMR spectrum (400 MHz, chloroform- $d$, $298 \mathrm{~K}$ ) of EtP6 $\beta$ after sorption of the PCT/OCT equimolar mixture vapor for $48 \mathrm{~h}$. 


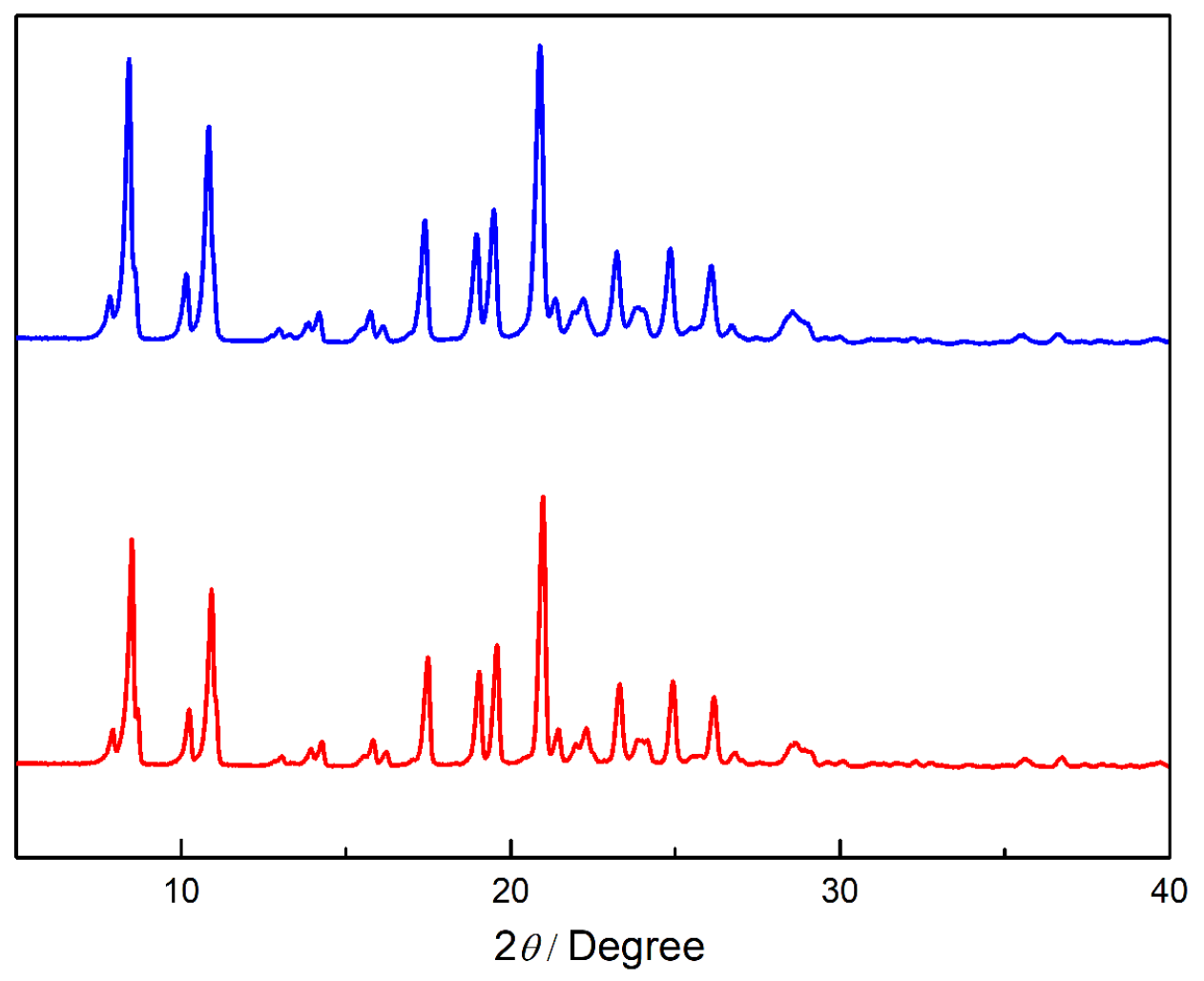

Figure S37. Powder X-ray diffraction patterns of EtP6: (I) EtP6 $\beta$ upon absorption of PCT vapor for $48 \mathrm{~h}$ (blue); (II) EtP6 $\beta$ upon absorption of the PCT/OCT equimolar mixture vapor for $48 \mathrm{~h}$ (red).

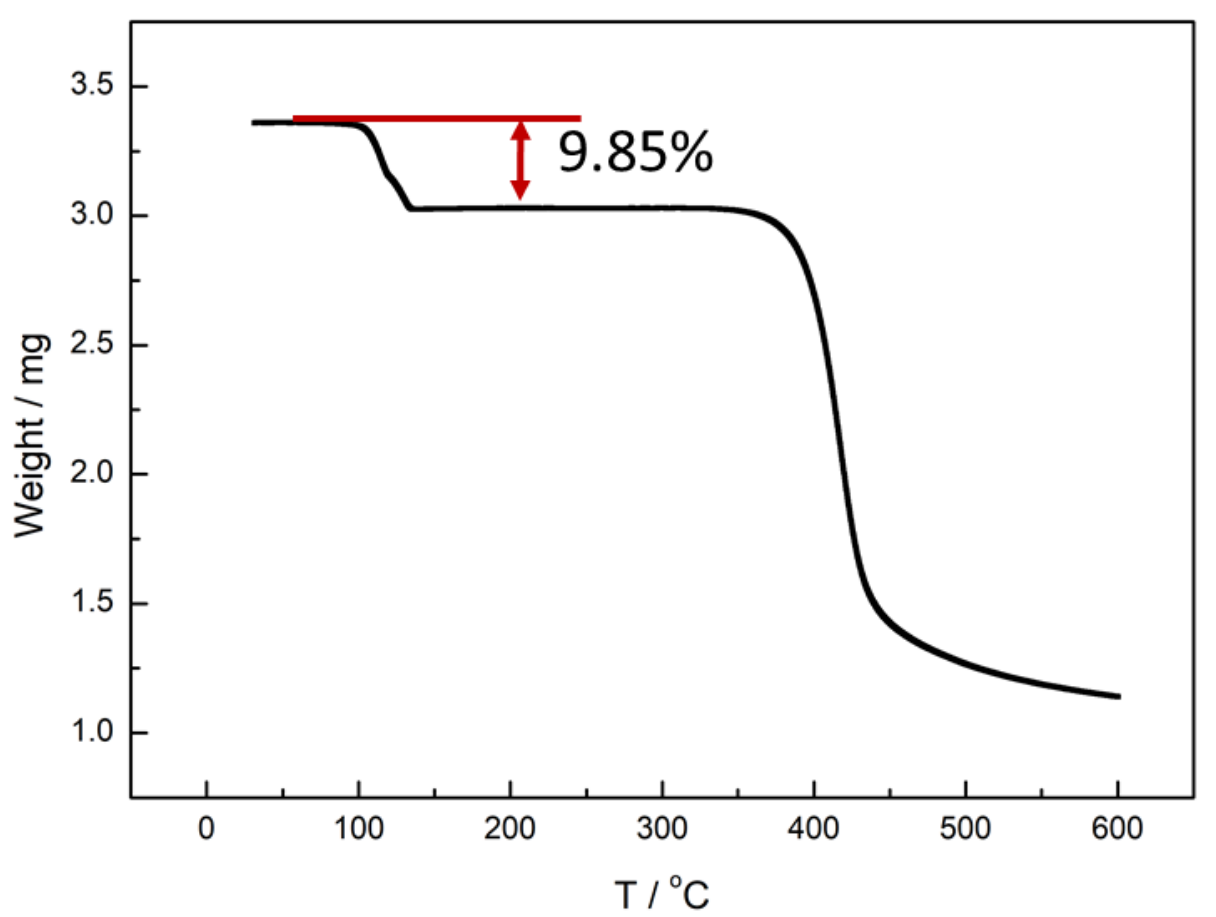

Figure S38. Thermogravimetric analysis of EtP6 $\beta$ after absorption of the PCT/OCT equimolar mixture vapor for $48 \mathrm{~h}$. The weight loss below $150{ }^{\circ} \mathrm{C}$ can be calculated as one PCT molecule per EtP6 molecule. 


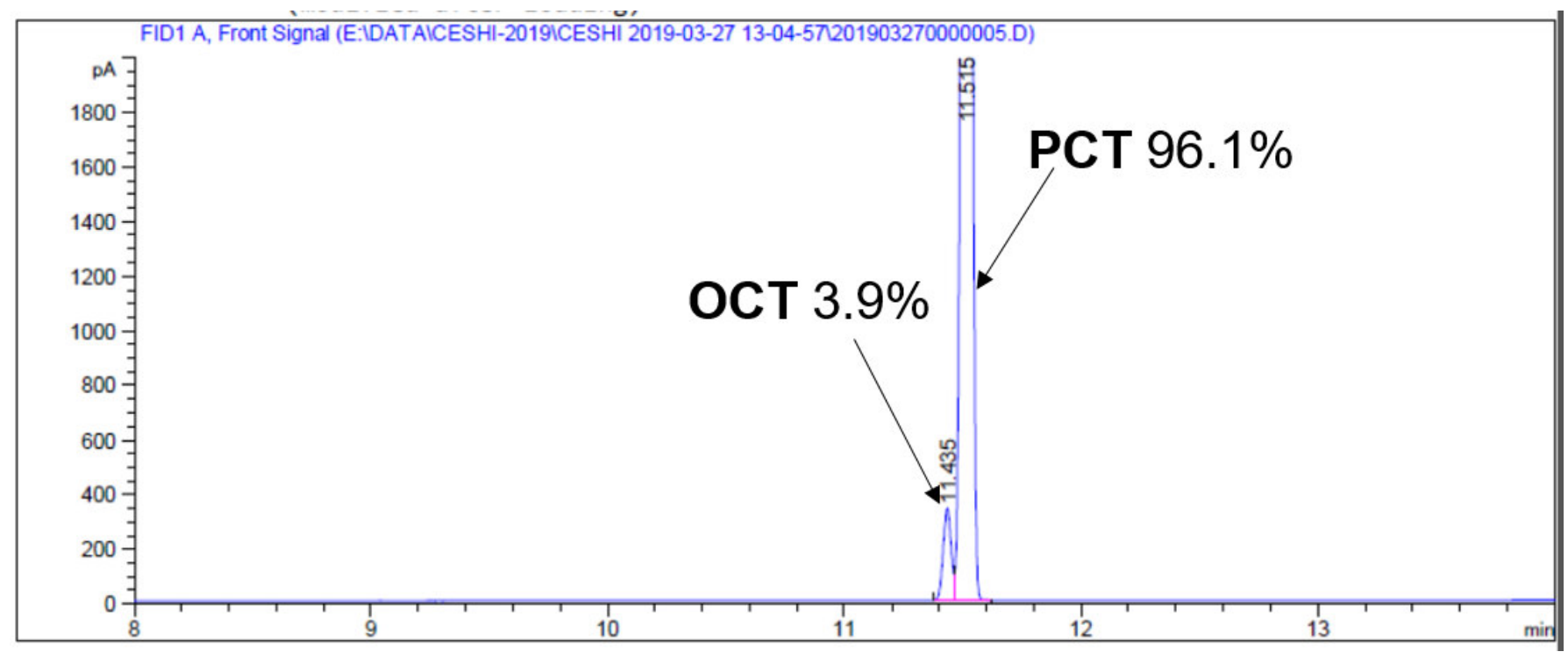

Figure S39. Relative uptakes of PCT and OCT adsorbed in EtP6 $\beta$ after absorption of the PCT/OCT equimolar mixture vapor for $48 \mathrm{~h}$ using head space gas chromatography. 
9.2. Separation of PCT from a Mixture Composed of PCT : OCT : MCT $=50: 49: 1(v: v: v)$ by EtP5 $\alpha$ and EtP6 $\beta$

An open $5 \mathrm{~mL}$ vial containing $20 \mathrm{mg}$ of guest-free EtP5 $\alpha$ or EtP6 $\beta$ adsorbent was placed in a sealed $20 \mathrm{~mL}$ vial containing $1 \mathrm{~mL}$ of a mixture composed of PCT : OCT : MCT = 50:49:1(v:v:v). The relative uptakes of PCT, OCT and MCT in $\operatorname{EtP5} \alpha$ or $\operatorname{EtP6} \beta$ were measured by heating to release the adsorbed vapor and detecting the relative amounts of monochlorotoluene isomers in the released vapor using gas chromatography. Before measurements, the crystals were heated at $50{ }^{\circ} \mathrm{C}$ for 30 min to remove the surface-physically adsorbed monochlorotoluene molecules.

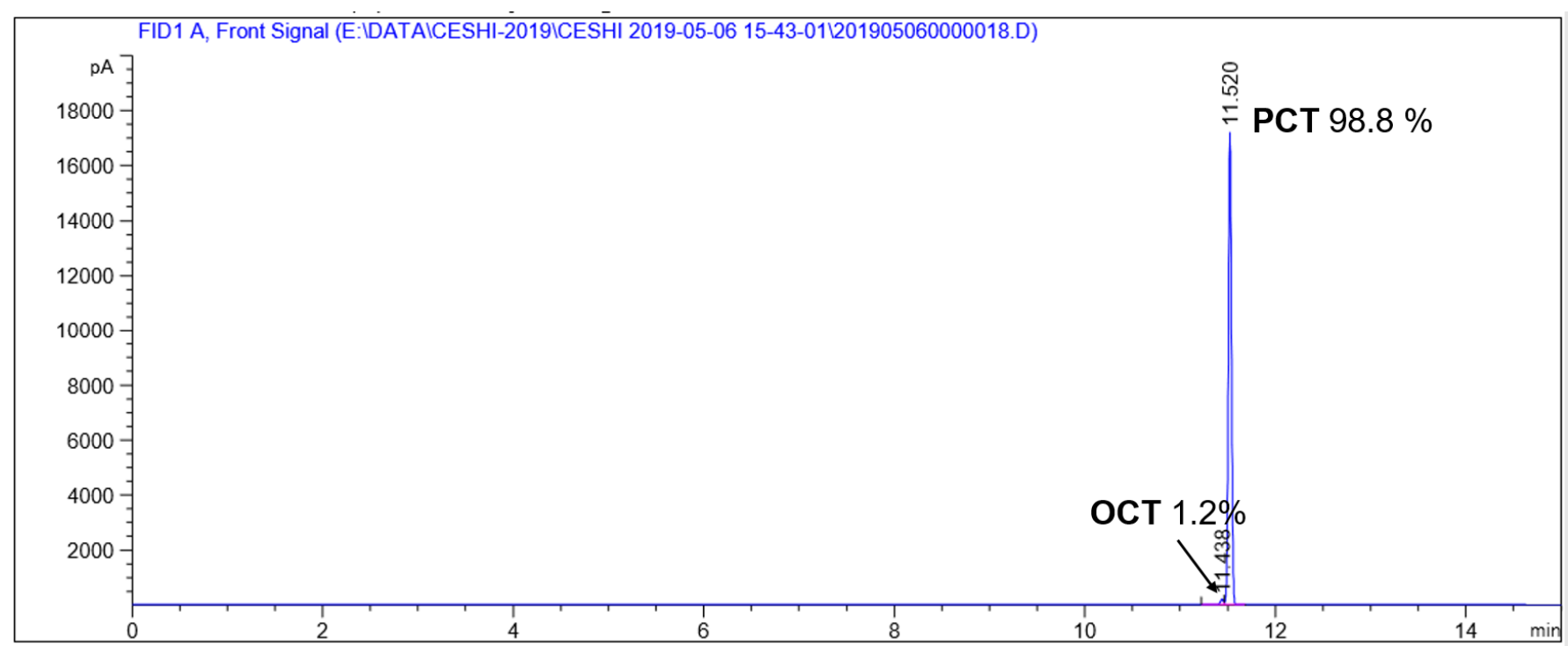

Figure S40. Relative uptakes of PCT, OCT and MCT adsorbed in EtP5 $\alpha$ after absorption of a PCT, OCT and MCT mixture ( $v: v: v=50: 49: 1)$ vapor for 48 hours using head space gas chromatography. 


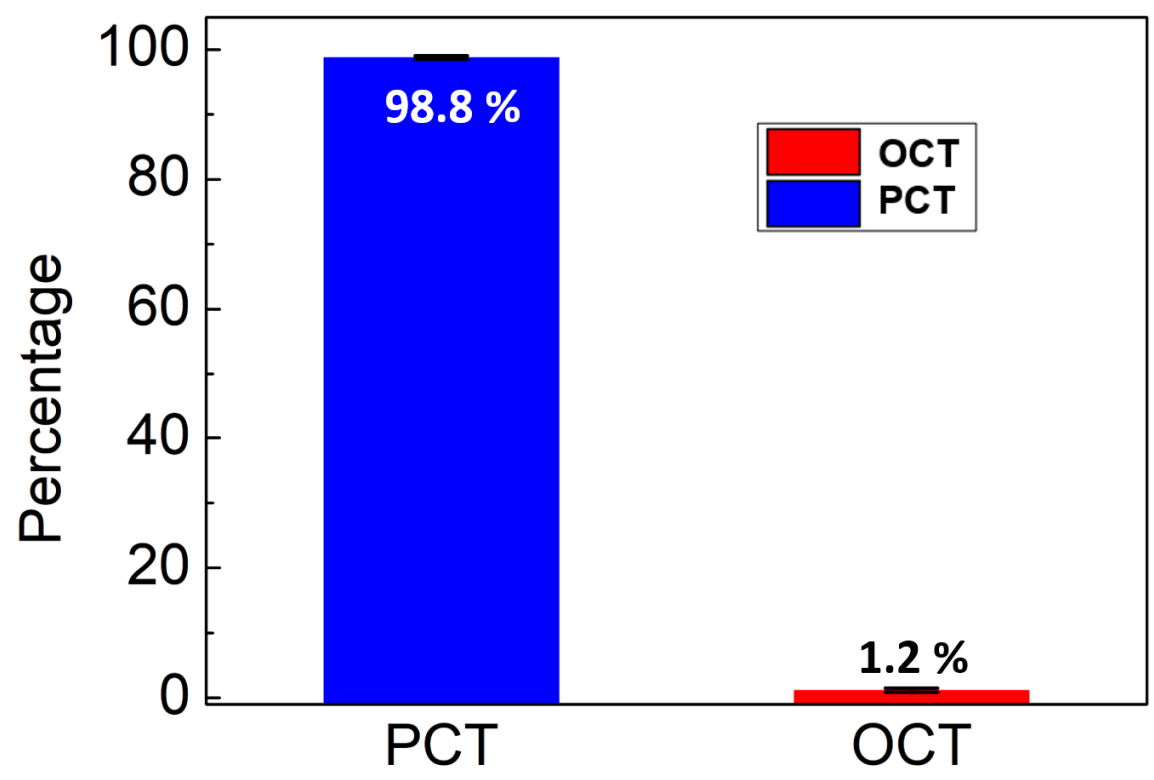

Figure S41. Relative amounts of PCT and OCT adsorbed in EtP5 $\alpha$ after saturated absorption of the PCT, OCT and MCT mixture ( $v: v: v=50: 49: 1)$ vapor.

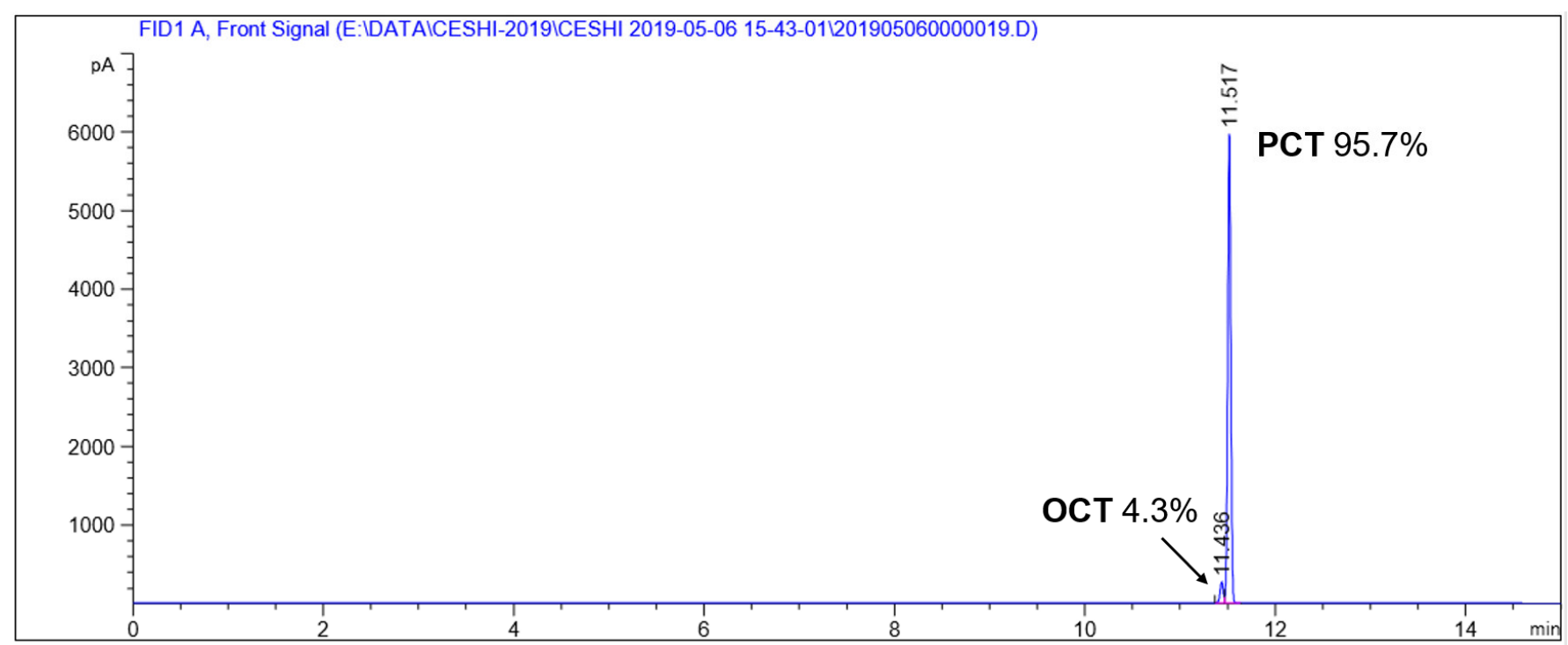

Figure S42. Relative uptakes of PCT, OCT, and MCT adsorbed in EtP6 $\beta$ after absorption of the PCT, OCT and MCT mixture ( $v: v: v=50: 49: 1)$ vapor for 48 hours using head space gas chromatography. 


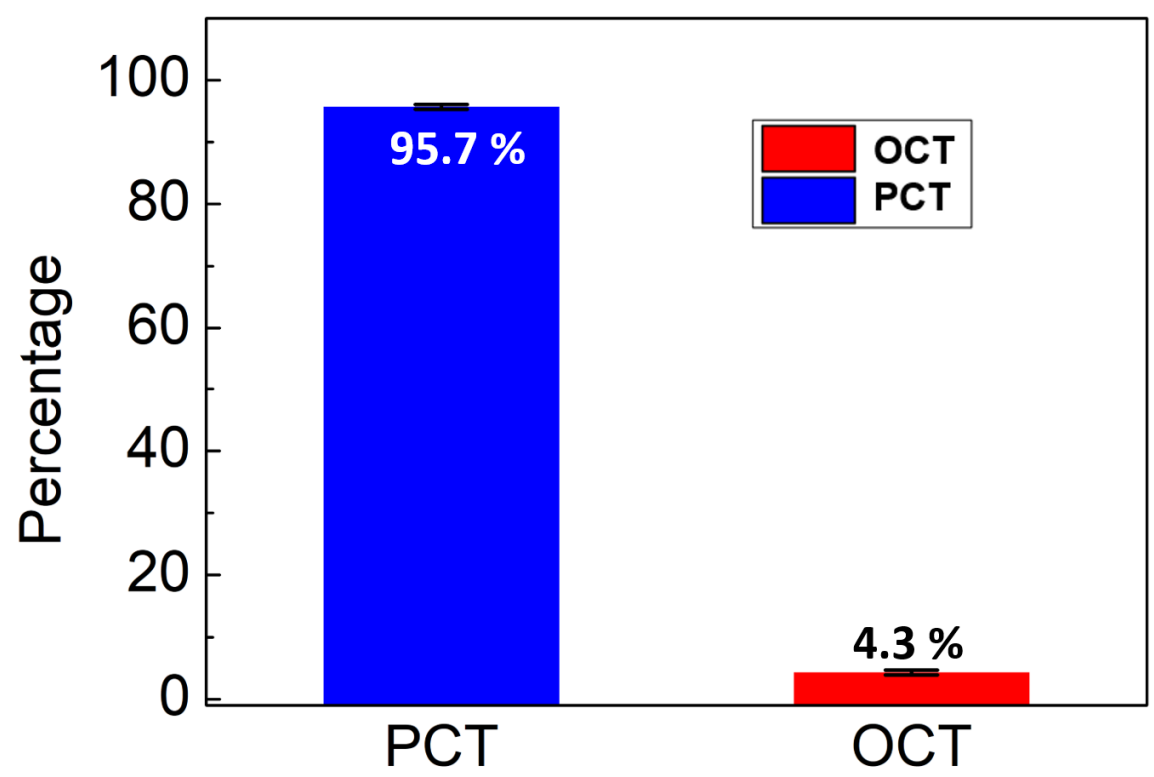

Figure S43. Relative amounts of PCT and OCT adsorbed in EtP6 $\beta$ after saturated absorption of the PCT, OCT and MCT mixture ( $v: v: v=50: 49: 1)$ vapor. 
10. Recyclability of EtP5 $\alpha$ and EtP6 $\beta$

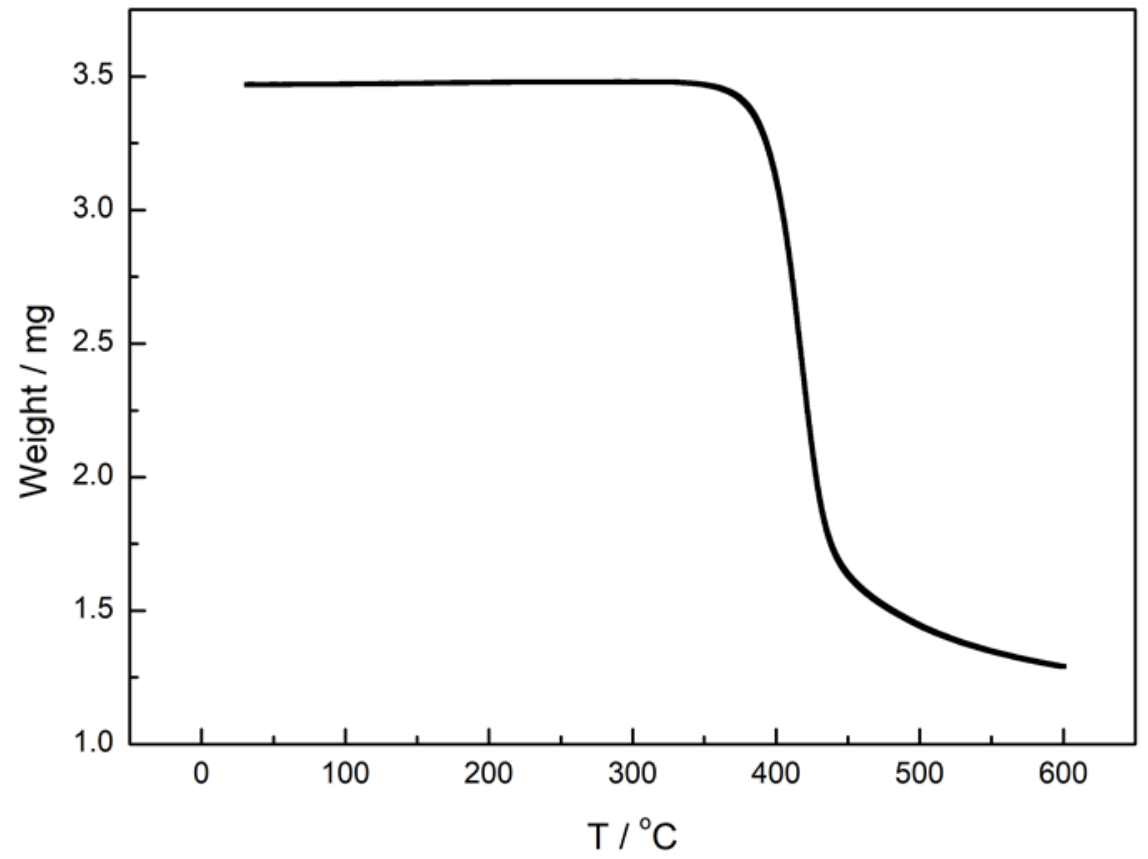

Figure S44. Thermogravimetric analysis of PCT-loaded EtP5 $\alpha$ after heating at $100{ }^{\circ} \mathrm{C}$ under vacuum for $2 \mathrm{~h}$.

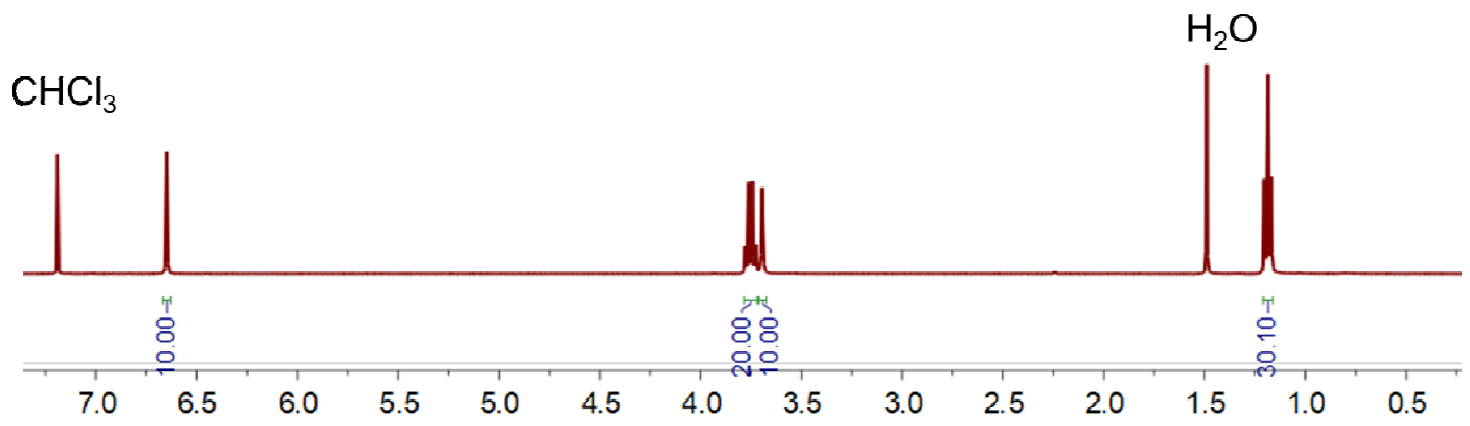

Figure S45. ${ }^{1} \mathrm{H}$ NMR spectrum (400 MHz, chloroform- $d$, $298 \mathrm{~K}$ ) of PCT-loaded EtP5 $\alpha$ after heating at $100{ }^{\circ} \mathrm{C}$ under vacuum for $2 \mathrm{~h}$. 


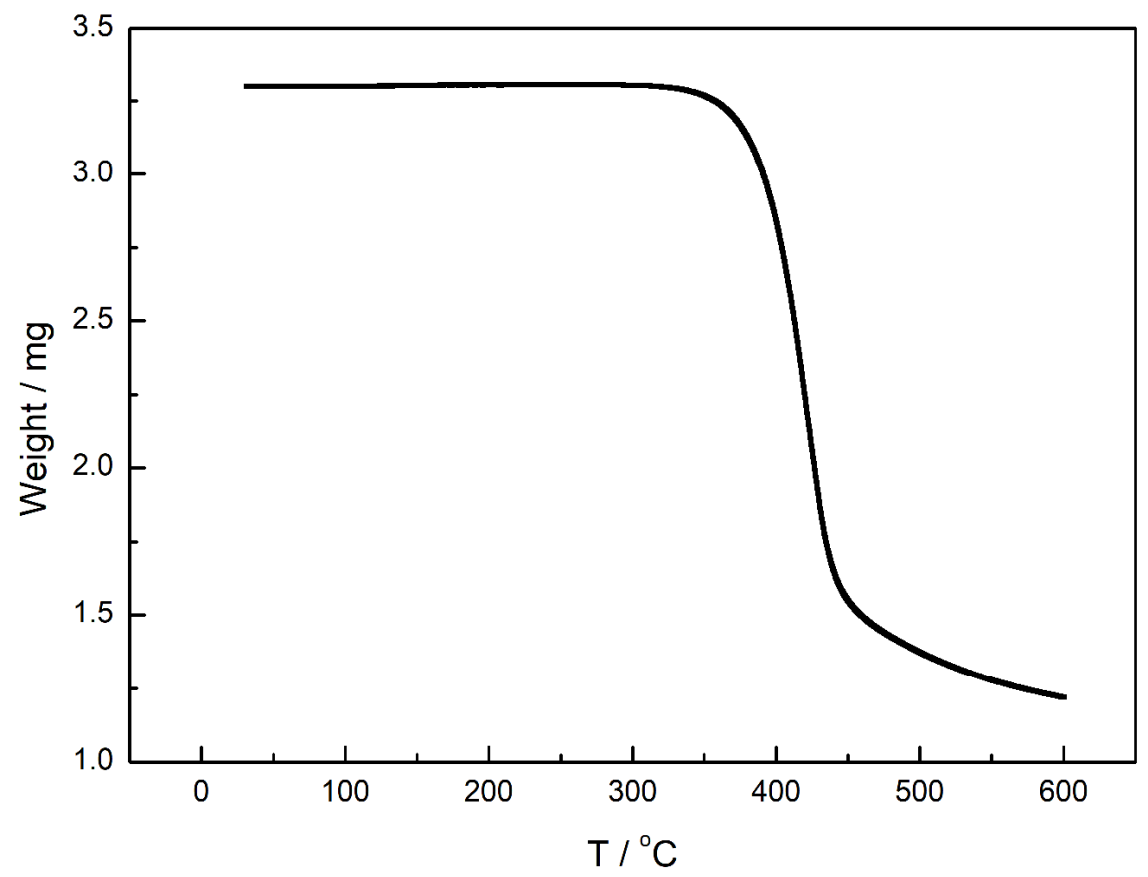

Figure S46. Thermogravimetric analysis of PCT-loaded EtP6 $\beta$ after heating at $100{ }^{\circ} \mathrm{C}$ under vacuum for $2 \mathrm{~h}$.

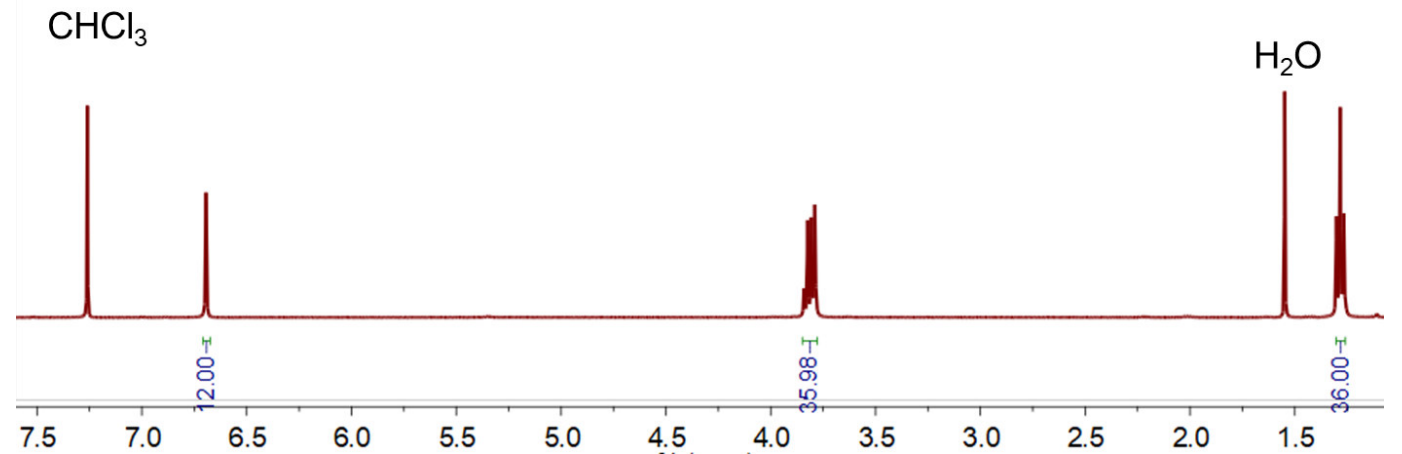

Figure S47. ${ }^{1} \mathrm{H}$ NMR spectrum (400 MHz, chloroform- $d$, $298 \mathrm{~K}$ ) of PCT-loaded EtP6 $\beta$ after heating at $100{ }^{\circ} \mathrm{C}$ under vacuum for $2 \mathrm{~h}$. 


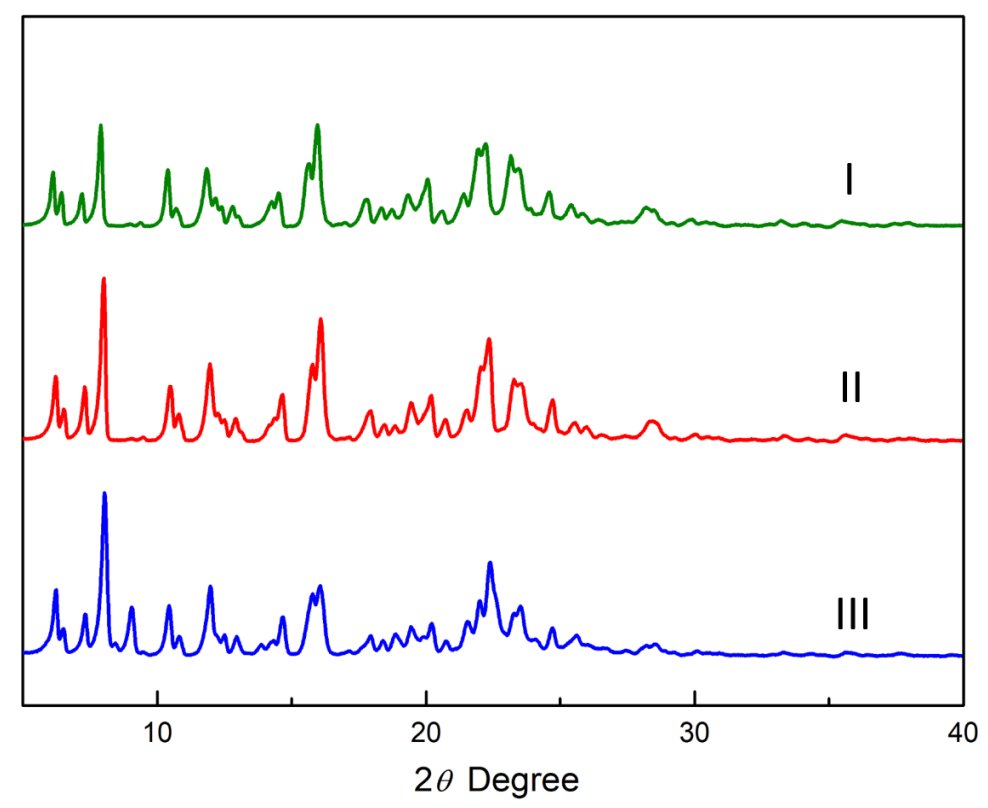

Figure S48. Powder X-ray diffraction patterns of EtP5: (I) original EtP5 $\alpha$ (green); (II) EtP5 $\alpha$ after heating at $100{ }^{\circ} \mathrm{C}$ under vacuum for $2 \mathrm{~h}$ (red); (III) EtP5 $\alpha$ after 5 cycles (blue).

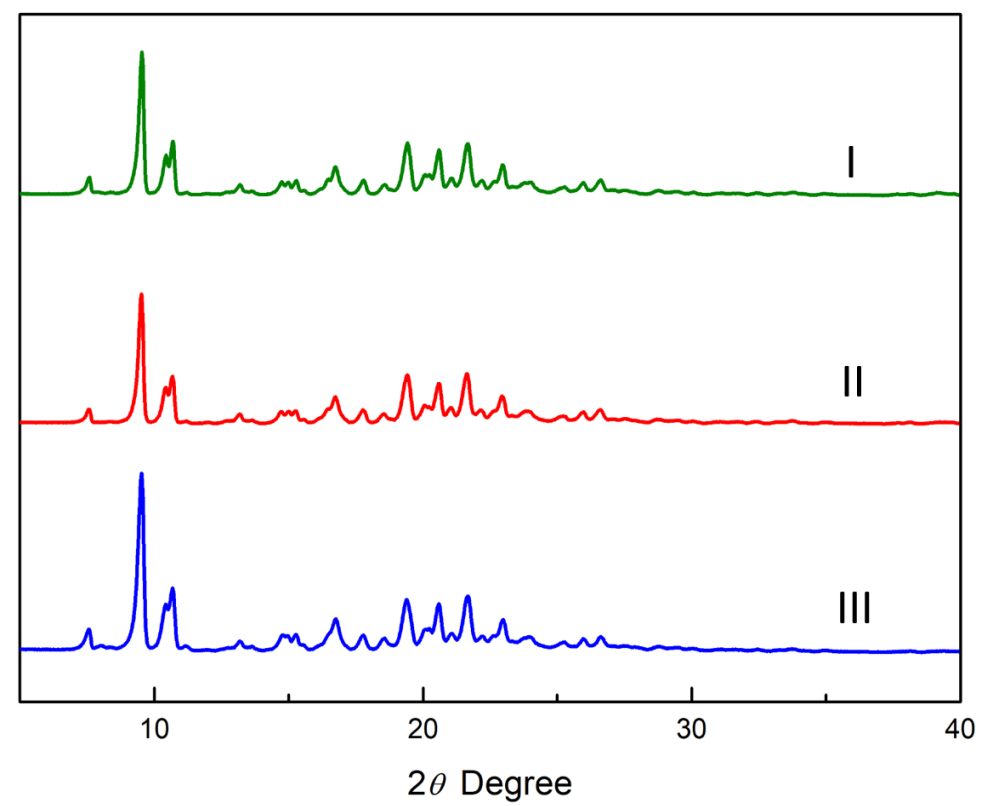

Figure S49. Powder X-ray diffraction patterns of EtP6: (I) original EtP6 $\beta$ (green); (II) EtP6 $\beta$ after heating at $100{ }^{\circ} \mathrm{C}$ under vacuum for 2 h (red); (III) EtP6 $\beta$ after 5 cycles (blue). 


\section{1. ${ }^{1} \mathrm{H}$ NMR spectra for Host-Guest Interactions Study in Solution}

The complexation between hosts and guests was investigated by ${ }^{1} \mathrm{H}$ NMR spectroscopy. Results showed that no chemical shift change happened to protons on PCT and OCT after addition of host molecules. And there was no chemical shift change found for protons on both EtP5 and EtP6. These results indicated that there was no host-guest interaction between host EtP5 or EtP6 and guest PCT or OCT in solution.<smiles>Clc1ccc(I)cc1</smiles>

PCT<smiles>Clc1ccccc1I</smiles>

OCT

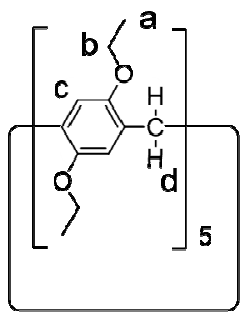

EtP5

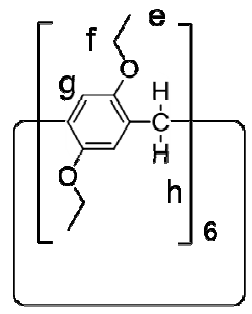

EtP6

Figure S50 Chemical structure of PCT, OCT, EtP5 and EtP6.

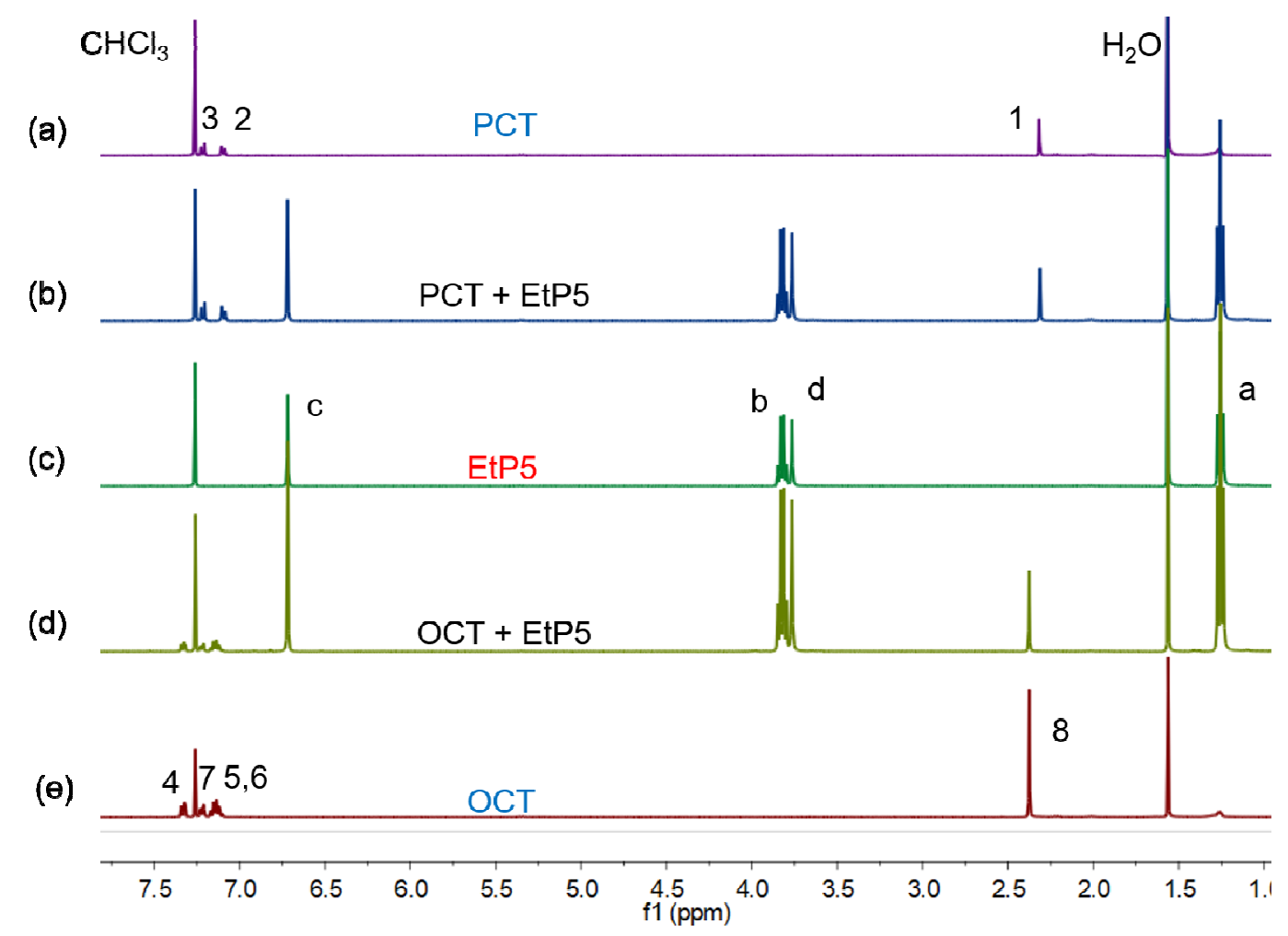

Figure S51 ${ }^{1} \mathrm{H}$ NMR spectra (400 MHz, $\left.\mathrm{CDCl}_{3}, 293 \mathrm{~K}\right)$ : (a) PCT (5.00 mM); (b) PCT (5.00 mM) + EtP5 (5.00 mM); (c) EtP5 (5.00 mM); (d) OCT (5.00 mM) + EtP5 (5.00 mM); (e) OCT (5.00 mM). 


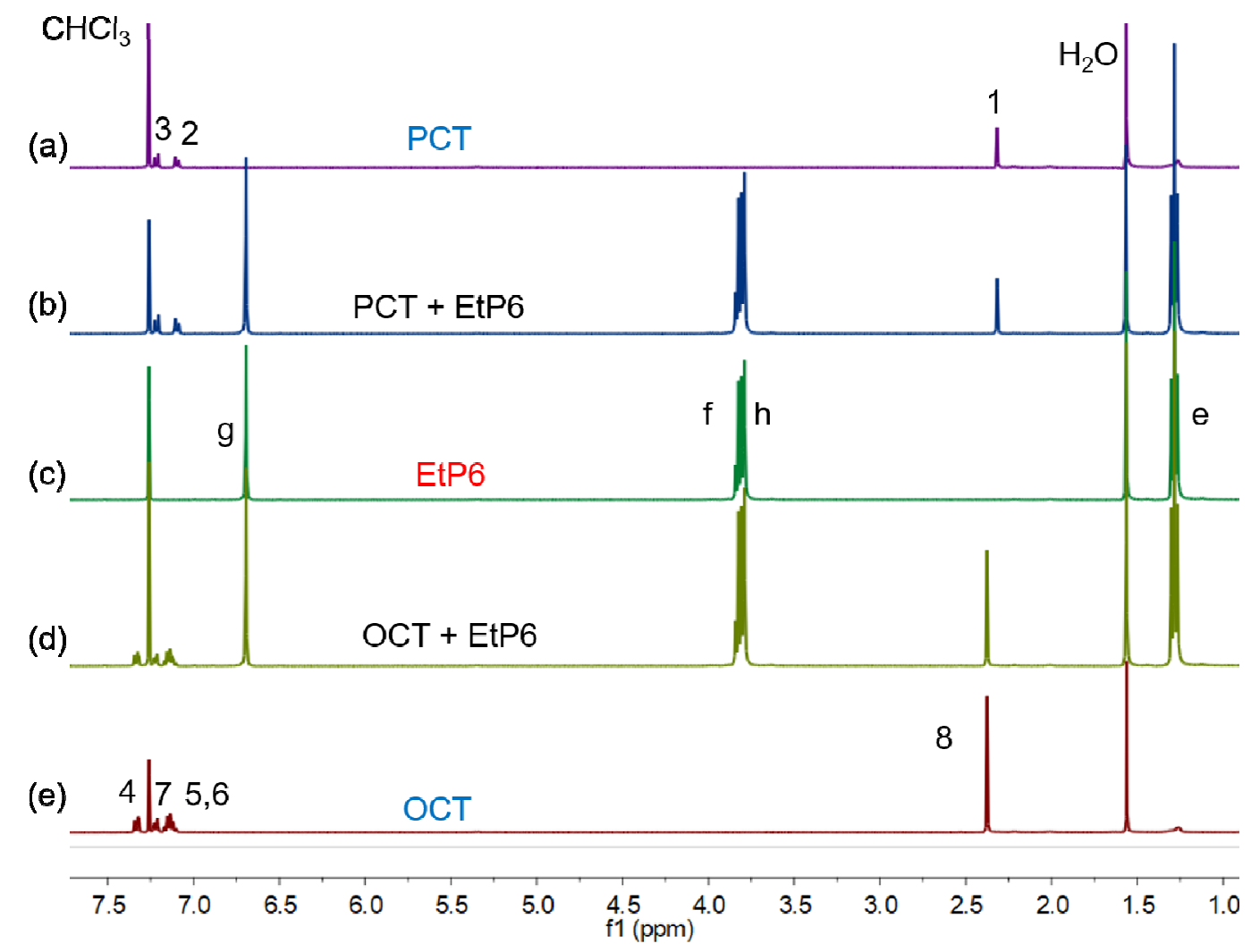

Figure S52 ${ }^{1} \mathrm{H}$ NMR spectra (400 MHz, $\left.\mathrm{CDCl}_{3}, 293 \mathrm{~K}\right)$ : (a) PCT (5.00 mM); (b) PCT (5.00 mM) + EtP6 (5.00 mM); (c) EtP6 (5.00 mM); (d) OCT (5.00 mM) + EtP6 (5.00 mM); (e) OCT (5.00 mM). 


\section{References}

S1. Hu, X.-B.; Chen, Z.; Chen, L.; Zhang, L.; Hou, J.-L.; Li, Z.-T. Pillar[n]arenes $(n=8-10)$ with two cavities: synthesis, structures and complexing properties. Chem. Commun. 2012, 48, 10999-11001.

S2. Jie, K.; Liu, M.; Zhou, Y.; Little, M. A.; Pulido, A.; Chong, S. Y.; Stephenson, A.; Hughes, A. R.; Sakakibara, F.; Ogoshi, T.; Blanc, F.; Day, G. M.; Huang, F.; Cooper, A. I. Near-Ideal Xylene Selectivity in Adaptive Molecular Pillar[n]arene Crystals. J. Am. Chem. Soc. 2018, 140, 6921-6930;

S3. Uno, S.; Kurihara, K.; Ochi, K.; Kojima, K. Determination and correlation of vapor-liquid equilibrium for binary systems consisting of close-boiling components. Fluid Phase Equilibr. 2007, 257, 139-146.

S4. Suezawa, H.; Yoshida, T.; Hirota, M.; Takahashi, H.; Umezawa, Y.; Honda, K.; Tsuboyama, S.; Nishio, M. The $\mathrm{CH}^{\cdots} \pi$ interaction as an important factor in the crystal packing and in determining the structure of clathrates. J. Chem. Soc., Perkin Trans. 2001, 2, 2053-2058.

S5. Zhang, Z.; Luo, Y.; Chen, J.; Dong, S.; Yu, Y.; Ma, Z.; Huang, F. Formation of Linear Supramolecular Polymers That Is Driven by $\mathrm{C}-\mathrm{H} \cdots \pi$ Interactions in Solution and in the Solid State. Angew. Chem. Int. Ed. 2011, 50, 1397-1401.

S6. Cheung, D. The Adverse Effects of Le Châtelier's Principle on Teacher Understanding of Chemical Equilibrium. J. Chem. Educ. 2009, 86, 514-518. 